\title{
PD-L1 checkpoint blockade delivered by retroviral replicating vector confers anti-tumor efficacy in murine tumor models
}

\author{
Leah A. Mitchell ${ }^{1}$, Kader Yagiz ${ }^{1}$, Andrew Hofacre ${ }^{1}$, Sophie Viaud ${ }^{1}$, Anthony W. \\ Munday ${ }^{1}$, Fernando Lopez Espinoza ${ }^{1}$, Daniel Mendoza ${ }^{1}$, Maria E. Rodriguez- \\ Aguirre $^{1}$, Simon Bergqvist ${ }^{2}$, Ali Haghighi ${ }^{1}$, Marin V. Miner ${ }^{1}$, William P. Accomando ${ }^{1}$, \\ Cynthia Burrascano ${ }^{1}$, Dawn Gammon ${ }^{1}$, Harry E. Gruber ${ }^{1}$, Douglas J. Jolly ${ }^{1}$ and Amy \\ H. Lin ${ }^{1}$ \\ ${ }^{1}$ Tocagen Inc., San Diego, 92121, CA, USA \\ ${ }^{2}$ Biofizik, Inc., San Diego, 92121, CA, USA \\ Correspondence to: Amy H. Lin, email: alin@tocagen.com \\ Keywords: immunotherapy; single chain variable fragment; retroviral replicating vector; PD-L 1; PD-1 \\ Received: January 08, $2019 \quad$ Accepted: March 04, $2019 \quad$ Published: March 19, 2019 \\ Copyright: Mitchell et al. This is an open-access article distributed under the terms of the Creative Commons Attribution License \\ 3.0 (CC BY 3.0), which permits unrestricted use, distribution, and reproduction in any medium, provided the original author and \\ source are credited.
}

\section{ABSTRACT}

Immune checkpoint inhibitors (CPIs) are associated with a number of immunerelated adverse events and low response rates. We provide preclinical evidence for use of a retroviral replicating vector (RRV) selective to cancer cells, to deliver CPI agents that may circumvent such issues and increase efficacy. An RRV, RRV-scFv-PDL1, encoding a secreted single chain variable fragment targeting PD-L1 can effectively compete with PD-1 for PD-L1 occupancy. Cell binding assays showed trans-binding activity on $100 \%$ of cells in culture when infection was limited to $5 \%$ RRV-scFvPDL1 infected tumor cells. Further, the ability of scFv PD-L1 to rescue PD-1/PD-L1 mediated immune suppression was demonstrated in a co-culture system consisting of human-derived immune cells and further demonstrated in several syngeneic mouse models including an intracranial tumor model. These tumor models showed that tumors infected with RRV-scFv-PD-L1 conferred robust and durable immune-mediated anti-tumor activity comparable or superior to systemically administered anti-PD-1 or anti PD-L1 monoclonal antibodies. Importantly, the nominal level of SCFv-PD-L1 detected in serum is 50-150 fold less than reported for systemically administered therapeutic antibodies targeting immune checkpoints. These results support the concept that RRV-scFv-PDL1 CPI strategy may provide an improved safety and efficacy profile compared to systemic monoclonal antibodies of currently approved therapies.

\section{INTRODUCTION}

A retroviral replicating vector (RRV) platform based on an amphotropic gamma retrovirus that preferentially infects and replicates in tumor cells has been developed to address historical challenges with viral-based treatments for cancer. One example of the RRV approach is Toca 511, (vocimagene amiretrorepvec), an RRV encoding optimized cytosine deaminase derived from yeast) used in combination with an oral prodrug, Toca FC (extended-release 5-fluorocytosine) which has demonstrated durable, complete responses and a favorable safety profile in a Phase 1 trial [1] and is currently in a fully enrolled Phase 3 trial in patients with recurrent high grade glioma (NCT02414165). In addition to its tumorselectivity, integration of RRV genome into the cancer cell genome allows sustained and localized therapeutic transgene expression in the tumor microenvironment and substantial bystander effects [2, 3]. Furthermore, unlike oncolytic viruses, RRV's non-lytic replication process does not trigger immediate anti-viral immune responses, allowing for sustained viral replication and therapeutic transgene expression in the tumor microenvironment $[4,5]$. 
Immune checkpoint inhibitors (CPI) such as therapeutic antibodies targeting cytotoxic $\mathrm{T}$ lymphocyte antigen 4 (CTLA-4), programmed death-1 (PD-1) and its ligand programmed death-1 ligand 1 (PD-L1) have represented a breakthrough for immunotherapies in treating cancer patients and have specifically made a significant impact in the fight against melanoma, lung, bladder head and neck cancer as well as in Hodgkin lymphoma [6]. However, there is still a substantial medical need that remains; the response rate ranges from $20-30 \%$ across tumor types with a number of immune-related adverse events associated with treatment to a high rate of treatment discontinuation ( $12-39 \%$ patients) [7-9]. In addition, among the approved CPIs, although PD-1 receptor occupancy has been demonstrated in circulating $\mathrm{T}$ cells following anti-PD-1 therapy $[10,11]$, it is unclear if complete saturation of PD-1 in circulating T cells serves as a surrogate biomarker for PD-1/L1 blockade in the tumor microenvironment (TME) $[12,13]$.

PD-1 is one of the major inhibitory receptors highly expressed on tumor infiltrating lymphocytes where upon its ligation with PD-L1 reduces cytokine production and T-cell proliferation resulting in immune escape from an active anti-tumor T-cell response in the TME [14]. In addition to the immune suppression mediated by PD-1/PD-L1 ligation, PD-L1 can also bind to CD80/B7.1 expressed on antigen presenting cells and block activation of T-cells through CD80/B7.1 binding to CD28 [15, 16]. PD-L1 expression is found in a broad range of tissues including $\mathrm{T}$ and $\mathrm{B}$ cells, dendritic cells, and macrophages [17]. PD-L1 upregulation is also found in tumor cells across many cancer types $[18,19]$. Its expression is associated with MAPK or PI3K oncogenic pathways and is induced by IFN- $\gamma$ thus representing an acquired mechanism of immune evasion $[19,20]$. As PD-L1 is a proven immunooncology target for many cancer types and its expression is not limited to cancer cells in the TME, use of an RRV to selectively deliver a PD-1/L1 blockade in the TME may have desirable properties.

We have previously reported a new RRV configuration utilizing the "self-cleavage" 2A peptide (RRV-2A) as an alternative of the internal ribosomal entry sequence (IRES) described in Toca 511 [21, 22]. The RRV-2A configuration allows insertion of therapeutic transgene(s) up to approximately $1.2 \mathrm{~kb}$ and high efficiency of polyprotein separation. Also, RRV-2A tolerates singleand multiple-therapeutic transgene insertion without compromising the viral genome stability, infectivity and transgene expression [21]. In the current study, we explored a strategy using RRV-2A encoding a secreted single-chain variable fragment targeting PD-L1 (RRV-scFv-PDL1) to deliver an immune CPI that may reduce systemic immune toxicities and enhance efficacy through selective delivery to the TME. Although oncolytic viruses encoding immune CPIs have been reported, the efficacy in delaying tumor progression is limited [23]. Here, we demonstrate that
RRV-scFv-PDL1 exhibits normal viral assembly and functions with a high level of genome stability. We also demonstrate that scFv PD-L1 effectively block PD-1/ PD-L1 interaction leading to alleviation of PD-1/PD-L1 mediated immune suppression in a co-culture system in vitro. This activity was further supported by data from multiple syngeneic mouse models showing that tumors infected with RRV-scFv-PDL1 conferred robust and durable immune-mediated anti-tumor activity comparable or superior to systemically administered anti-PD1 and anti-PD-L1 monoclonal antibodies. Most importantly, our data show that only nominal level of scFv-PD-L1 was found in the circulation in mouse models where significant efficacy was observed. These results support the concept of an RRV-based platform for delivery of an immune CPI for an improved therapeutic window compared to systemic monoclonal antibodies currently approved for clinical use in many cancer types.

\section{RESULTS}

\section{scFv PD-L1 encoded in the RRV-2A configuration is expressed and properly processed}

We have previously reported a new RRV configuration utilizing the viral-derived "self-cleavage" 2A peptide for transgene expression [21] and demonstrated that RRV-2A configuration can tolerate transgene insertion up to $1.2 \mathrm{~kb}$. In the current study, we designed two different configurations of a single-chain variable fragment ( $\mathrm{scFv}$ ) against PD-L1. One consists of $\mathrm{scFv}$ alone and another with the Fc from human IgG1, designated pAC3-scFvPDL1 and pAC3-scFvFc-PDL1, respectively. Due to the absence of an antibody against scFv PD-L1 protein, we also generated a matching pair of the constructs with an $\mathrm{HA}$ and Flag epitope incorporated at the C-terminus of the transgene, designated pAC3-scFv-HF-PDL1 and pAC3scFvFc-HF-PDL1 (Figure 1A).

We have also previously shown that transgenes targeted for different cellular compartments encoded inframe with the viral envelope (Env) protein in the RRV-2A configuration, are efficiently separated from Env-transgene polyprotein [21]. Because both the epitope tagged and untagged $\mathrm{scFv}$ PD-L1 and scFvFc PD-L1 proteins are designed to be separated from the viral Env protein and secreted from the cells, we used a transient transfection system to highly overexpress the transgene proteins to aid the detection of epitope tagged scFv PD-L1 and scFvFc PDL1 proteins. Cell lysates from transiently transfected 293 T cells were resolved on SDS-PAGE and detected with anti-HA and anti-Flag antibody to confirm the presence of scFv PD-L1 and its separation efficiency mediated by the 2A peptide, respectively. In addition, an anti-2A antibody was also included to confirm the proper processing of the viral Env protein from the polyprotein. Figure 1B shows that both scFv-HF PD-L1 and scFvFc-HF PD-L1 are 
detected and separated from the polyprotein as expected, and that the viral Env protein is properly processed to its subunits as indicated by the detection of 15E-2A [21]. The residual unseparated polyprotein detected is also expected as the cell lysates are from transiently transfected system in which the protein is highly overexpressed, and it was previously shown that such unseparated polyprotein is not incorporated into viral particles [21].

A

CMV-R-U5

U3-R-U5

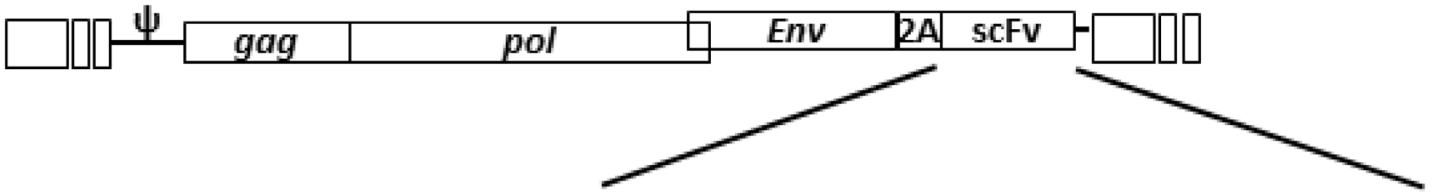

scFv

scFvFc

\begin{tabular}{l|l|} 
GS & $\mathrm{V}_{\mathrm{L}}$ \\
\hline
\end{tabular}

scFv-HF

$\operatorname{IgG}_{1} \mathrm{FC}$

scFvFc-HF

\begin{tabular}{|l|l|l|l|l|l|}
\hline $\mathrm{V}_{\mathrm{H}}$ & $\mathrm{GS}$ & $\mathrm{V}_{\mathrm{L}}$ & $\mathrm{IgG}_{1} \mathrm{FC}$ & $\mathrm{H}$ & $\mathrm{F}$ \\
\hline
\end{tabular}

B
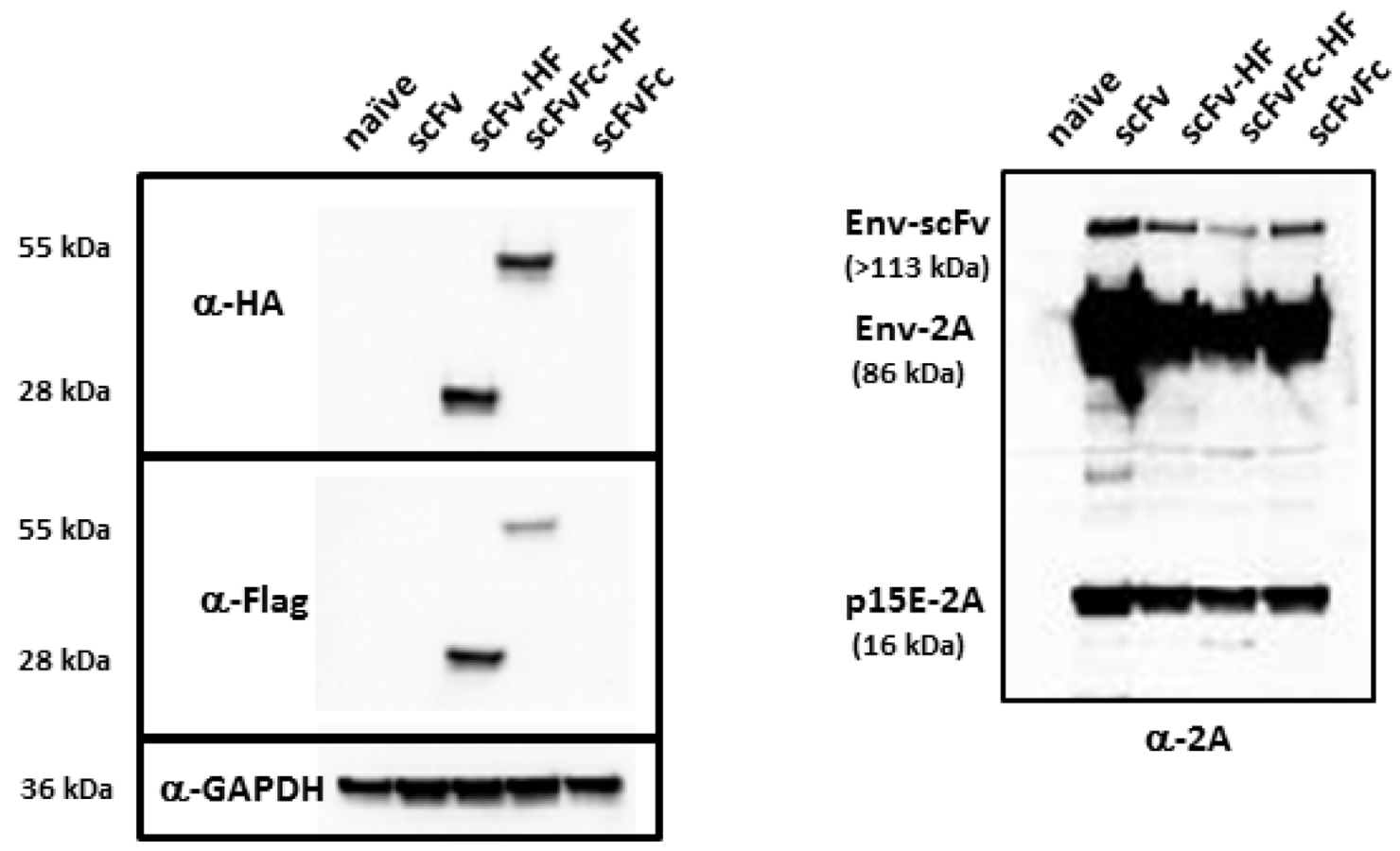

Figure 1: Schematic diagram of RRV-scFv-PDL1 plasmid DNAs. (A) Two pairs of single-chain variable fragment (scFv) against PD-L1 were encoded in pAC3 RRV backbone. One pair consists of scFv with and without the Fc from human IgG1, designated as pAC3-scFv-PDL1 and pAC3-scFvFc-PDL1, respectively. Another pair consists of scFv-PDL1 and scFvFc-PDL1 with HA and Flag epitope incorporated at the C-terminus, designated as pAC3scFvHF-PDL1, pAC3-scFvFc-HF-PDL1. Filled rectangle indicates leader sequence derived from human IL-2. (B) Western blot analysis of viral envelope proteins produced transient transfection in 293T cells. Twenty micrograms of total protein lysates were loaded per well. Membranes were incubated (left panel) with anti-HA and anti-Flag antibody which detects HA- and Flag-tagged scFv-PD-L1 and scFvFc-PD-L1, respectively, or (right panel) with anti-2A peptide antibody which detects Env-scFv polyprotein (Env-scFv), unprocessed viral precursor envelop protein separated from the Env-scFv polyprotein (Env-2A), and processed viral envelop protein tagged with the 2A peptide at the C-terminus (p15E-2A). Anti-GAPDH antibody (lower left panel) was included as loading control. 


\section{RRV vectors encoding ScFv-PDL1 and scFvFc-PDL1 replicate efficiently and exhibit high level of genome stability}

We next evaluated the viral function of both epitope tagged (HA and Flag) and untagged RRV-scFv-PDL1 and RRV-scFvFc-PDL1 vectors, as proper viral Env processing is an important determinant for viral replication [24]. We first measured the viral titer produced from transiently transfected 293T cells. Our data indicate that there were no significant differences in titers produced among the four vectors from transient transfection (Supplementary Table 1). In addition, viral replication kinetics of all four vectors were monitored in a conventional human glioma cell line U87-MG, and Toca 511 was included as a control and a comparator. Figure $2 \mathrm{~A}$ shows that with equal input of multiplicity of infection (MOI) at the initial infection, all four vectors replicated efficiently in U87-MG cells with no delay observed compared to Toca 511 .

Another key factor which could influence the therapeutic effect of the transgene is vector stability. We have previously showed that the RRV-2A can tolerate a large transgene(s) insertion up to $1.2 \mathrm{~kb}$ [21]. In the current study, the long-term vector genome stability of RRV-scFv-PDL1 and RRV-scFvFc-PDL1 in U87-MG cells was followed for a total of 16 infection cycles. The proviral DNA from maximally infected cells at each infection cycle were harvested for PCR. Our data indicate that the viral genome of both RRV-scFv-PDL1 and RRVscFvFc-PDL1 remained stable throughout the 16 cycles of infection (Figure 2B). Interestingly, the data also indicate that RRV-2A configuration can tolerate a transgene size of $1.6 \mathrm{~kb}$ (scFvFc transgene) which is $0.4 \mathrm{~kb}$ larger than the thymidine kinase transgene previously reported [21].

\section{scFv PD-L1 and scFvFc PD-L1 secreted from RRV-scFv-PDL1 and RRV-scFvFc-PDL1 infected cells competes with PD-1 for PD-L1 binding}

Having confirmed the transgene protein expression and viral function of RRV-scFv-PDL1 and RRV-scFvFcPD-L1, we evaluated the binding characteristics of $\mathrm{scFV}$ PD-L1 and scFvFc PD-L1. The potency of scFv PDL1 and scFvFc PD-L1 protein to block PD-1/PD-L1 interaction was evaluated using an ELISA-based competition assay to quantify the amount of His-tagged PD1 that remained bound to PD-L1 after coincubation of recombinant PD-L1Fc with scFv PD-L1 or scFvFc PD-L1 protein. Although the concentration of the scFv PD-L1 and scFvFc PD-L1 in the supernatant is undefined, they specifically bound to human PD-L1 and mouse PD-L1 in a dose-dependent manner. The level of inhibition using $100 \mu \mathrm{L}$ of the supernatant was comparable to that of the blocking antibody control with no significant difference between scFv PD-L1 and scFvFc PD-L1 (Figure 3A). The potency of scFv PD-L1 and scFvFc PD-L1 in blocking mouse PD-1/PD-L1 interaction appears to be effective though slightly less potent than with the human counterpart but more effective than the anti-mouse PD-L1 antibody (Figure 3B). To further evaluate the binding activity of $\mathrm{scFv} P D-$ L1 on human PD-1/PD-L1, we compared the blocking activity of purified ScFv PD-L1 to that of the anti-human PD-L1 antibody. Despite of its monovalent property, scFv PD-L1 exhibits an approximately 10-fold higher blocking activity (01C; than anti-human PD-L1 antibody (Figure 3C, IC50 = 5.821 nM vs. $45.89 \mathrm{nM}$ ). We also characterized the binding kinetics of $\mathrm{scFv}$ PD-L1 to human and mouse PD-L1 using the surface plasmon resonance system. The scFv PD-L1 cDNA was cloned into a CMV-driven expression vector for transient transfection followed by purification to obtain $>85 \%$ purity. The equilibrium dissociation constant $\left(\mathrm{K}_{\mathrm{D}}\right)$ of $\mathrm{scFv}$ PD-L1 for recombinant human PD-L1 and mouse PD-L1 were determined to be $0.426 \mathrm{nM}$ and $4.78 \mathrm{nM}$, respectively, (Supplementary Figure 1). The approximately 10-fold higher binding affinity to human PD-L1 as a result of slower $\mathrm{K}_{\text {off }}$ could explain the higher potency of scFv PDL1 in blocking human PD-1/PD-L1 interaction observed in the competitive ELISA.

\section{scFv PD-L1 secreted from RRV-scFv-PDL1 infected cells exhibits bystander trans-binding activity to PD-L1 on the cell surface}

As infection of $100 \%$ of patient tumor cells in situ is not currently feasible by any viral-based therapeutic approach including RRV, we designed a secreted transgene product with the capacity to bind PD-L1 on neighboring, uninfected cells. Here, we employed a cell-based assay to confirm antigen-specific binding of scFv PD-L1 or scFvFc PD-L1 by flow cytometry. In this experiment, we used the epitope tagged scFv PD-L1 and scFvFc PD-L1 (scFvHF PD-L1 and scFvFc-HF PD-L1) followed by anti-HA antibody for detection. The data show that scFvHF PD-L1 and scFvFc-HF PD-L1 bind to PD-L1 expressed on cell surfaces in human and mouse cell lines as indicated by a marked shift in mean fluorescent intensity (MFI) with an anti-HA antibody (Supplementary Figure 2). A higher shift in MFI observed with scFvFc-HF PD-L1 in both the human and mouse cell lines tested is likely due to bivalent dimer of scFvFc-HF PD-L1 and hence simply a reflection of more anti-HA antibody bound to scFvFc-HF PD-L1 on the cell surface, rather than increased binding affinity, as the scFvFc PD-L1 did not compete more effectively than scFv PD-L1 in the ELISA (Figure 3A and 3B). Furthermore, the antigen binding specificity was demonstrated by blocking the accessibility of an anti-PD-L1 blocking antibody to PDL1 on the cell surface when co-incubated with the anti-HA antibody, resulting in a marked decrease in the MFI with the anti-PD-L1 antibody staining (Supplementary Figure 2). Consistent with the data observed in the competitive ELISA, scFv-HF PD-L1 and scFvFc-HF PD-L1 bind specifically to 
A

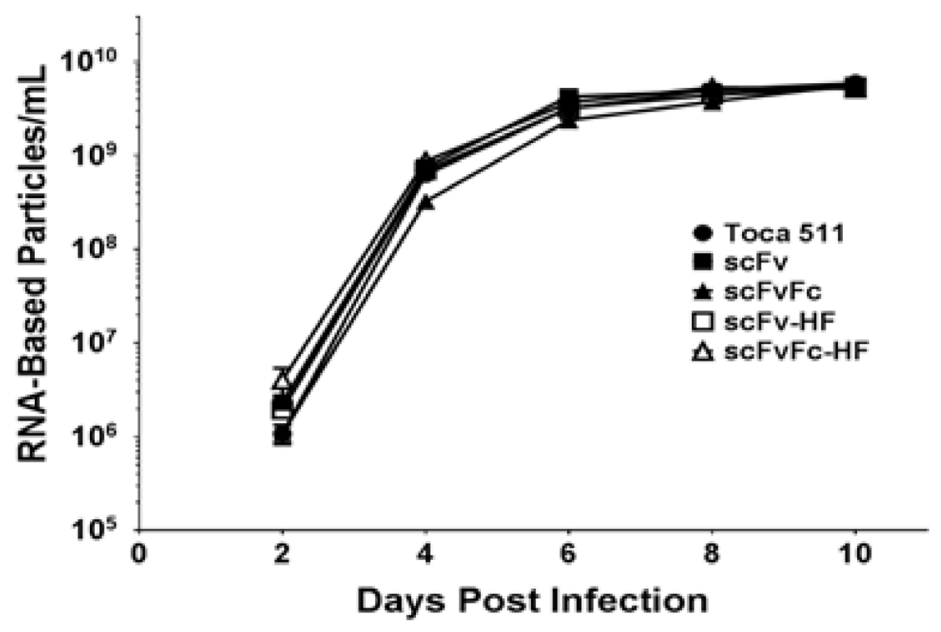

B

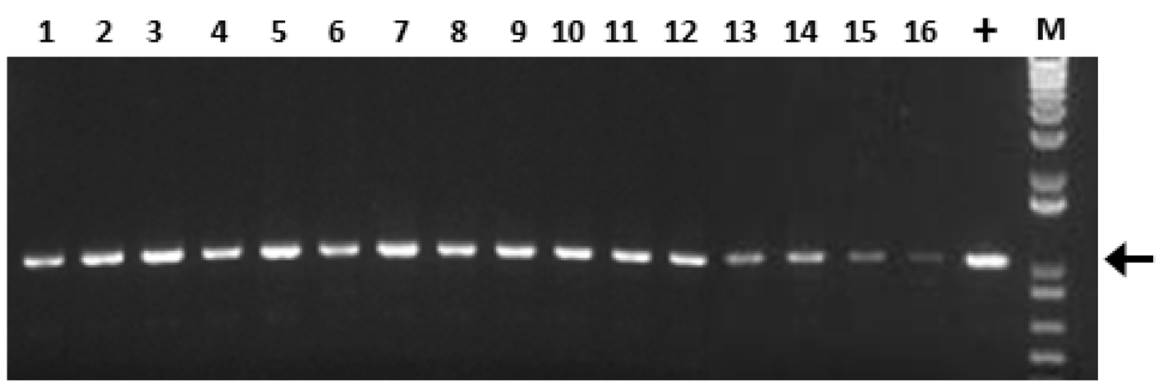

RRV-scFvFC-PDL1


Figure 2: Replication kinetics and genome stability of RRV-scFv-PDL1 and RRV-scFvFc-PDL1 vectors. (A) Viral genomes isolated from the viral supernatant of during the course of infection in U87-MG cells were quantified by RT-qPCR using primers spanning the viral envelope region. Infected cells were passaged every other day during the 10 days of infection and supernatants collected at each indicated time point prior cell passage. Data shown represent one of three independent experiments. Toca 511 (a.k.a. RRV-IRESyCD2) was included as controls. Data shown represent one of the two independent experiments with each experiment performed in triplicates. Values represent mean \pm SD. (B) Genome stability of RRV-scFv-PDL1 and RRV-scFvFc-PDL1 in U87-MG cells over a total of 16 infection cycles. Positive controls are PCR products amplified from plasmid DNA. Arrows indicate expected size of the PCR products. $\mathrm{M}$ indicates DNA molecular ladder (1 Kb Plus, Life Technologies). 
PD-L1 on the cell surface and block anti-PD-L1 antibody binding to PD-L1, suggesting the epitope for scFv-HF PDL1 and scFvFc-HF PD-L1 overlaps or is in proximity to that of the anti-PD-L1 antibody. In addition, the marked decrease in the MFI with anti-PD-L1 antibody also suggests full receptor (PD-L1) occupancy on the cell surface.

We have previously demonstrated in tumor mouse models that approximately $10-15 \%$ transduction level of Toca 511 in the tumor prior to initiation of 5-FC treatment is required to achieve long-term survival benefit through an immune-mediated bystander effect, and a minimal of at least $2-3 \%$ transduction to achieve some therapeutic benefit $[2,21]$. To evaluate the bystander effect of RRVscFv-PD-L1 in vitro, we tested the minimal transduction level required to achieve full receptor occupancy on tumor cells. In this experiment, EMT6 mouse breast cancer cells maximally infected with RRV-scFv-HF-PDL1, mixed with EMT6 cells maximally infected with RRV-GFP at various ratios were co-cultured to measure bound scFVHF PD-L1 and unbound PD-L1 on the cell surface using the anti-HA and anti-PD-L1 antibody. Our data show that bound scFvHF PD-L1 was detected on all cell surfaces when only $5 \%$ of the cells express scFvHF PD-L1 (Figure 4A). The full occupancy of PD-L1 inversely correlates with the decrease in PD-L1 signal on the cell surface in a dose dependent manner (Figure 4B), suggesting that $\mathrm{scFv}$ PD-L1 can achieve $100 \%$ bystander effect with a minimal level of transduction.
A



B

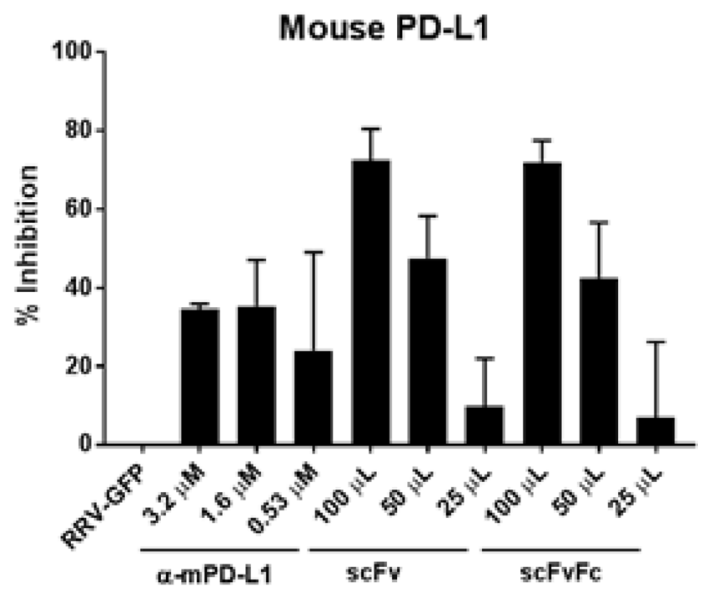

C

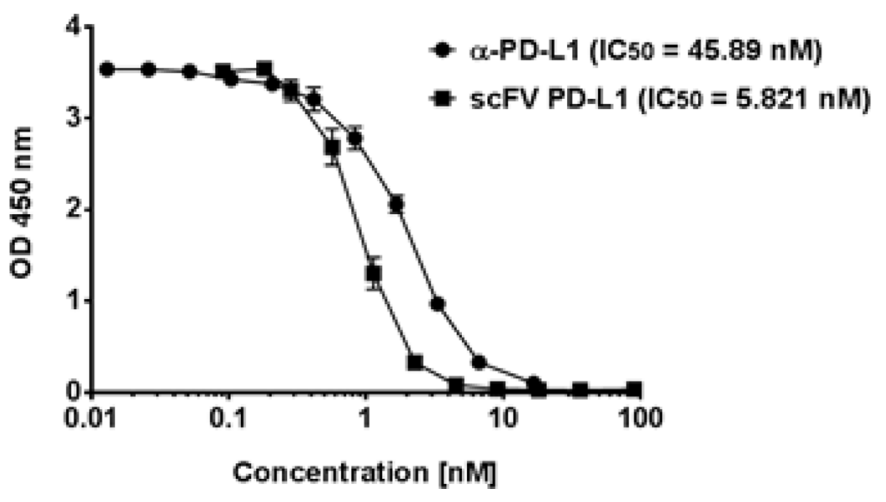

Figure 3: Detection of ScFv PD-L1 binding to PD-L1 by competitive ELISA. Wells in a 96-well microtiter plate were coated with (A) recombinant human or (B) mouse PD-L1-Fc followed by co-incubation with His-tagged recombinant PD-1-Fc in competition with 25,50 or $100 \mu \mathrm{L}$ of supernatant of undefined scFv PD-L1 (scFv) and scFvFc PD-L1 (scFvFc) protein concentration collected from CT26 cells maximally infected with RRV-scFv-PDL1 and RRV-scFvFc-PDL1, respectively. Anti-human or mouse PD-L1 antibody was included as positive control (indicated as $\alpha$-hPD-L1 and $\alpha-\mathrm{mPD}-\mathrm{L} 1$ ). Anti- His tag antibody was used to detect bound His-tagged PD-1-Fc. Optical density was measured at $450 \mathrm{~nm}$. The percentage of inhibition was calculated with respect to the supernatant from CT26 maximally infected with RRV-GFP (non-scFv-PD-L1) used in the competition. Error bars indicate the standard deviation of the dataset. (C) Wells were coated with recombinant human PDL1-Fc followed by co-incubation with His-tagged recombinant PD-1-Fc in competition with purified scFv PD-L1 or anti-human PD-L1 antibody range from 0.01-100 nM. IC50 values were determined using best-fit values from non-linear three-parameters logistic. 


\section{scFv PD-L1 rescues PD-1/PD-L1 mediated immune suppression in vitro}

As we have demonstrated that scFv PD-L1 binds to human PD-L1 with sub-nanomolar affinity and competes effectively with PD-1 for PD-L1 binding, we asked whether the blockade of PD-1/PD-L1 interaction in a cell-based system leading to immune suppression can be rescued by scFv PD-L1. In this experiment, we used an in vitro co-culture system previously described to demonstrate PD-1/PD-L1 mediated T-cell immune suppression [25]. The system was first validated to confirm that all signaling components for stimulation are present on Jurkat T-cells and Raji B-cells to respond to stimulation by the super antigen staphylococcal enterotoxin E (SEE), (Supplementary Figure 3A and 3B). We then generated Jurkat $\mathrm{T}$ cells and Raji B cells overexpressing human PD-1 and human PD-L1, respectively, by lentiviral vector transduction (Supplementary Figure 3C). Consistent with reported data, stimulation by SEE in the absence of

A

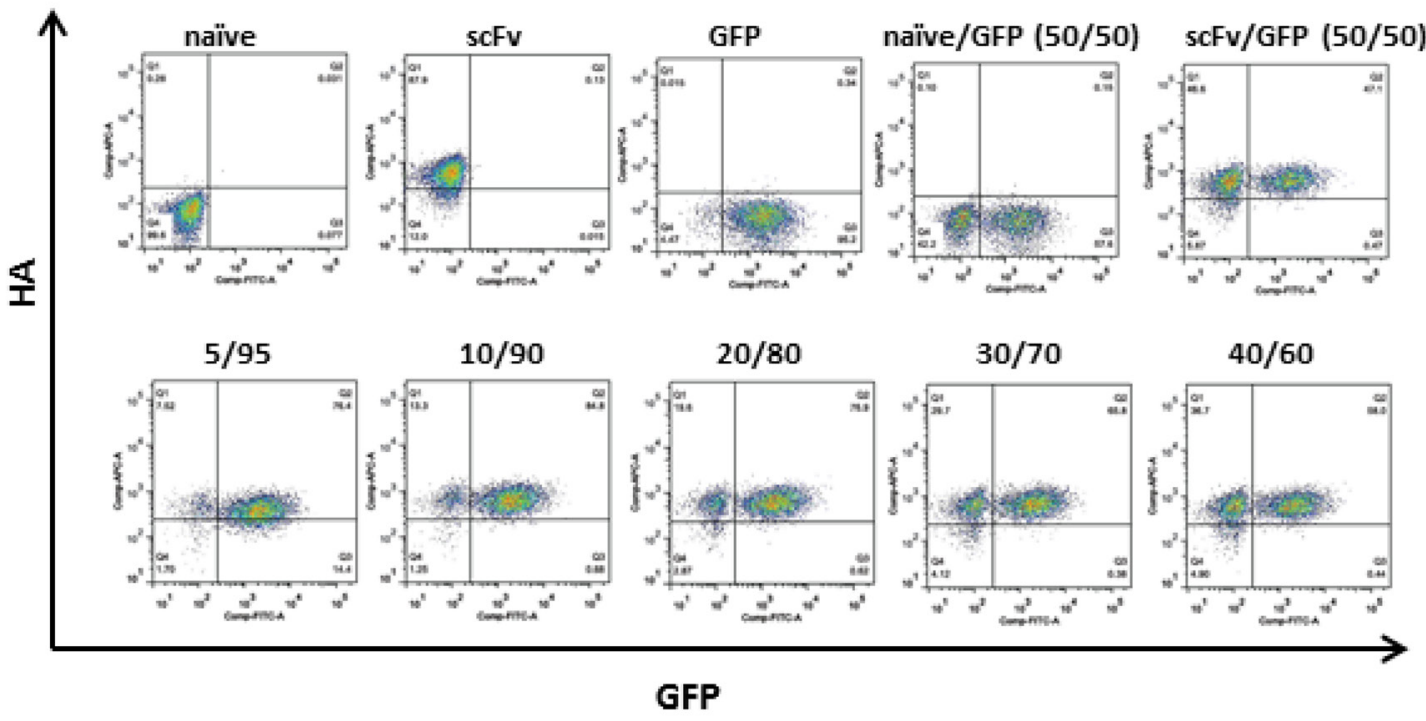

B

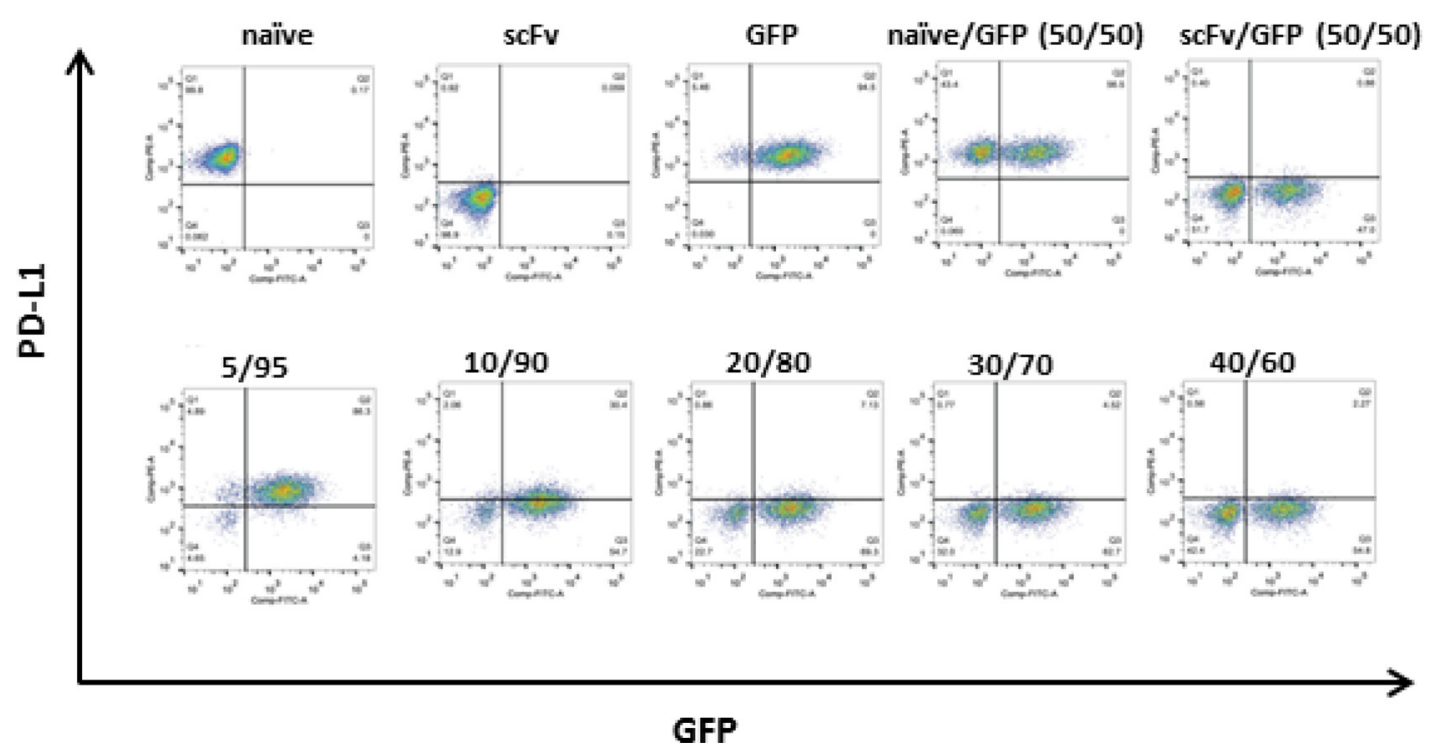

Figure 4: scFv PD-L1 trans-binding activity to PD-L1 on the cell surface of bystander cells. IFN $\gamma$-treated EMT6 cells maximally infected with RRV-scFv-HF PDL1 (HA-tagged scFv-PD-L1) or RRV-GFP at ratios indicated in parenthesis were split into 2 sets. (A) One set of cells was stained with Alexa Fluor 647-conjugated anti-HA antibody and (B) the second set of cells was stained with PE-conjugated anti-mouse PD-L1 antibody. HA-positive, PD-L1-positive, and GFP-positive cell populations were measured by flow cytometric analysis. 
PD-1/PD-L1 engagement led to a large quantity of IL-2 production by the Jurkat T cells, whereas PD-1/PD-L1 engagement led to a $>75 \%$ decrease in IL-2 production as a phenotypic indication of immune suppression (Figure 5). Importantly, in agreement with the binding characterization data described above, ScFv PD-L1 effectively blocked PD-1 for PD-L1 engagement and rescued the T-cell immune suppression mediated by PD-1/PD-L1.

\section{scFv PD-L1 and scFvFc PD-L1 treatment lead to tumor growth inhibition in a dose dependent manner and elicit immune memory response in syngeneic tumor models}

To translate the bystander effect and immune function of $\mathrm{scFv}$ PD-L1 observed in vitro to anti-tumor activity in vivo, we first sought to evaluate the anti-tumor immune activity mediated by scFv PD-L1 and scFvFc PDL1 in a CT26 mouse model which is commonly used for testing the efficacy of checkpoint inhibitors with marginal anti-tumor activity when administered as a monotherapy $[26,27]$. In this experiment, increasing percentages of CT26 cells pre-transduced with RRV-scFv-PDL1 or RRVscFvFc-PDL1 vector were prepared to evaluate survival with viral spread occurring during tumor growth. Tumor implants of RRV pre-transduced at 2\%, 30\% and 100\% expressing scFv PD-L1 or scFvFc PD-L1 were assessed for survival over time in comparison to untreated tumorbearing mice. The results indicate that the hazard ratios for tumor expressing scFv PD-L1 or scFvFc PD-L1 range from 0.384 to 0.7 relative to that of untreated mice (Supplementary Figure 4). For tumors that expressed scFv PD-L1, as low as $2 \%$ pre-transduced tumor was sufficient to provide survival benefit and the expression of IgG1 Fc as part of the scFvFc PD-L1 intended for improving protein stability or biodistribution of $\mathrm{scFvFc}$ PD-L1 appears to be dispensable as it did not improve survival benefit over ScFv PD-L1 expressing tumors in all 3 ratios tested. Notably, anti-PD-1 blocking antibody treatment, with dosing in a pre-staged tumor setting, did not provide survival benefit.

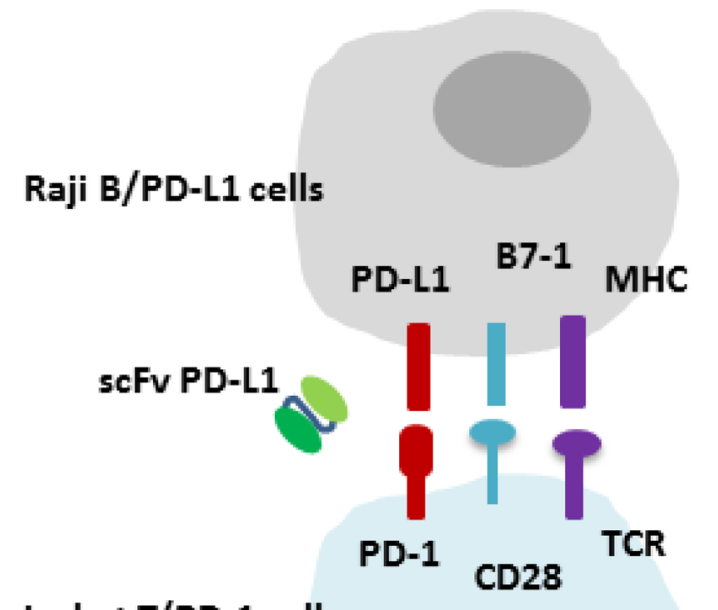

Jurkat T/PD-1 cells

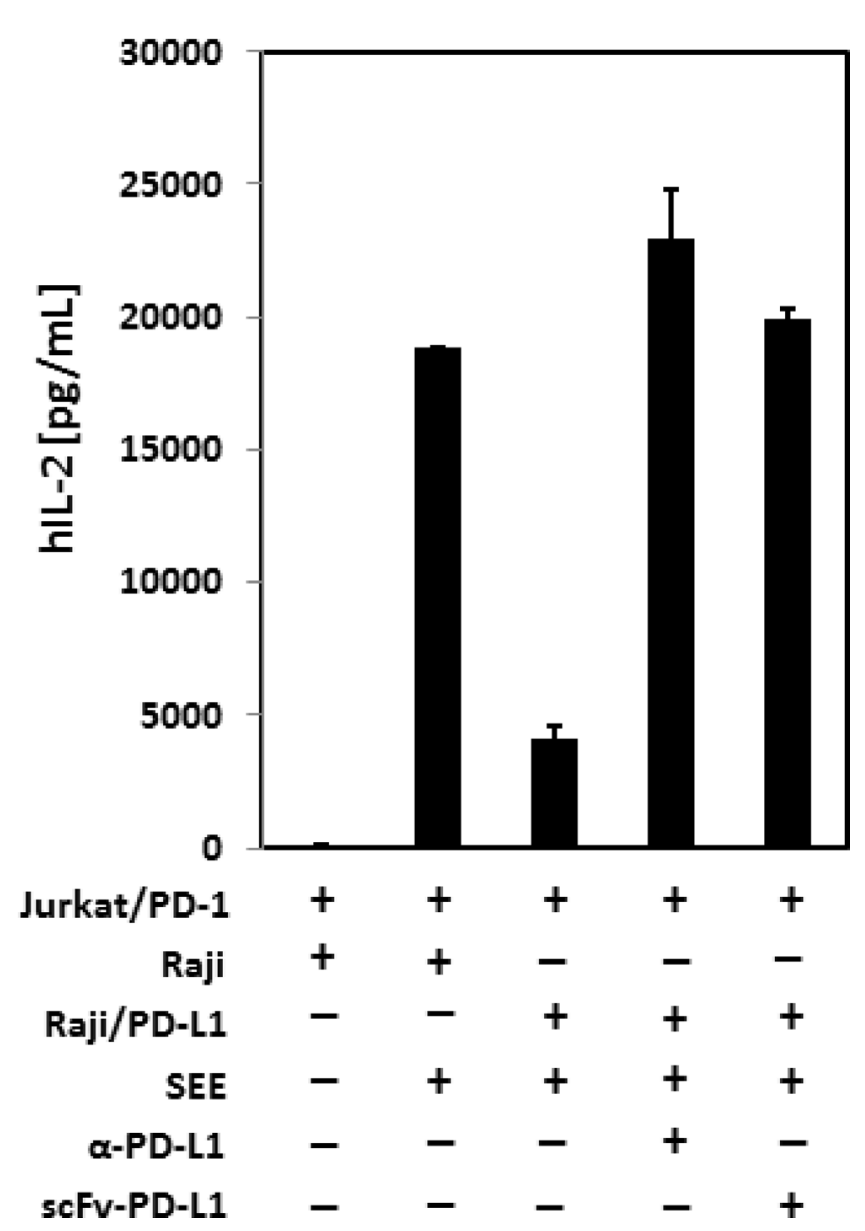

Figure 5: In vitro immune function of scFv PD-L1. Mixtures of SEE loaded, SEE + anti-human PD-L1 (10 $\mu \mathrm{g} / \mathrm{mL})$ or SEE + purified scFv-PD-L1 $(10 \mu \mathrm{g} / \mathrm{mL})$ Raji B cells or Raji B cells overexpressing human PD-L1 (with rested Jurkat T cells overexpressing human PD-1) were co-cultured in RPMI-1640 medium containing 10\% human AB serum for stimulation for 20-22 hours followed by IL-2 measurement by ELISA. 
We have shown that in vitro scFv PD-L1 secreted from as low as 5\% pre-transduced cells exhibited bystander trans-binding activity, leading to a full PDL1 occupancy on the cell surface of non-scFv PD-L1 expressing cells. We next evaluated the dose response of the anti-tumor activity of ScFv PD-L1 in a syngeneic orthotopic EMT6 breast cancer model which has been reported to be responsive to checkpoint inhibitors $[28,29]$. To evaluate the anti-tumor activity of scFv PD-L1 and scFvFc PD-L1 in a more clinically relevant scenario, we sought to determine the minimal transduction level required for $\mathrm{scFv}$ PD-L1 to achieve anti-tumor activity, using different ratios of EMT6 cells maximally pretransduced with RRV-scFv-PDL1, RRV-scFvFc-PDL1 or RRV-GFP vectors. These cells are resistant to further RRV infection mediated via the amphotropic envelope protein due to receptor down regulation [21]. The data show that mice bearing tumors with $2 \%, 30 \%$ and $100 \%$ scFv PDL1 or scFvFc PD-L1 expression trend toward a survival benefit compared to untreated mice, and a statistical significance was observed between the untreated and 30\% $\mathrm{scFvFc} / \mathrm{scFvFc}_{\mathrm{V}}$ group (Supplementary Figure 5A). We further sought to investigate whether mice that survived from the primary tumor have established an anti-tumor immune memory response by re-challenging them with naïve EMT6 tumor cells on the flank. Data revealed that mice that cleared tumor with $\mathrm{scFv} / \mathrm{scFvFc}$ treatment in the primary setting exhibited a moderate delayed tumor growth in a re-challenge setting, suggesting that an antitumor immune response was established in these mice (Supplementary Figure 5B). Together, these data indicate that tumor cells expressing scFv PD-L1 or scFvFc PD-L1 can lead to anti-tumor activity that appears to be superior to treatment with an anti-mouse PD-1 antibody.

We have previously reported on a subcutaneous Tu2449SC tumor model in B6C3F1 mice to elucidate the immune-mediated mechanism of action of Toca 511 and Toca FC [2]. We also tested this tumor model to determine the minimal transduction level required for scFv PD-L1 to exert anti-tumor activity. Consistent with data from the two tumor models described above, Figure 6A shows that in the Tu-2449SC tumor model, mice bearing tumor with as low as $2 \%$ Tu-2449SC cells expressing scFv PDL1 led to a delay in tumor progression that is comparable to anti-PD-1 antibody treatment, but not statistically significant when compared to untreated mice (Figure 6A). With 30\% pre-transduced cells, tumor progression was strongly inhibited as also seen in mice bearing tumors with the $100 \%$ pre-transduced cells. In this model, mice that cleared tumor with $\mathrm{scFv}$ treatment in the primary setting exhibited a strong memory anti-tumor response in a rechallenge setting (Figure 6B). Expectedly, the benefit of $\mathrm{Fc}$ in $\mathrm{scFvFc}$ PD-L1 was again not observed in this tumor model. Intriguingly, the inclusion of $\mathrm{Fc}$ at higher ratios (30\% and 100\% scFvFc PD-L1) seems to reduce its antitumor activity (Supplementary Figure 6).
To demonstrate PD-1/L1 blockade is associated with enhanced tumor lymphocyte infiltration, in a separate experiment, mice from each assigned group that had measurable tumor growth were extracted at day 39 post tumor implantation for lymphocyte profiling. The data show that treatment with ScFv PD-L1 resulted in a modest increase in $\mathrm{CD} 8+$ and a significant increase in CD4+ cells across all 3 groups when compared to the control group which have tumors with 100\% RRV-GFP cells (Figure 6C and 6D).

To further demonstrate that the anti-tumor activity of $\mathrm{ScFV}$ PD-L1 is immune-mediated and requires functional T-cells, a comparison of Tu-2449SC tumor progression was conducted in immune competent B6C3F1 mice and in an immune-deficient athymic mouse which lack functional T cells. As expected, Tu-2449SC tumor growth was delayed in $\mathrm{B} 6 \mathrm{C} 3 \mathrm{~F} 1$ mice, whereas in athymic mice, Tu-2449SC tumor growth progressed without delay (Supplementary Figure 7).

\section{Intracranial injection of RRV-scFv-PDL1 prolongs survival in syngeneic orthotopic glioma model}

The intracranial anti-tumor activity of immune checkpoint inhibitors have been clinically investigated recently in patients with recurrent glioblastoma (GBM) and preliminary data demonstrated a failure of antiPD-1 treatment as a monotherapy to prolong survival (Checkmate 143, NCT 02017717) [30, 31]. Despite the fact that a significant number of tumors expressed PDL1 in GBM [32], the pre-clinical evidence supporting the anti-tumor activity of anti-PD-1/PD-L1 has been limited to one orthotopic syngeneic glioma model [33-35]. Thus, we investigated scFv PD-L1 anti-tumor activity in an orthotopic syngeneic glioma model previously reported to respond to Toca 511 and Toca FC treatment [3] and employed an intra-tumoral RRV delivery approach previously established [3]. RRV-scFv-PDL1 viral functions and genome stability in maximally infected Tu-2449 cells were confirmed in vitro (Supplementary Figure 8). In this experiment, two different doses of RRV-scFv-PDL1 (1E5 and 1E6 TU) were delivered by a single intra-tumoral injection 4 days after tumor implant. Our data show that a single administration of 1E6 TU of RRV-scFVPDL1 is equally effective as Tu-2449 cells maximally pre-transduced with RRV-scFv-PDL1 (Figure 7A). Further, consistent with observation made in the previous experiments, subcutaneous re-challenge of Tu-2449SC tumor cells at a remote site from the primary tumor showed a systemic anti-tumor immune response leading to significant delay in tumor growth compared to naïve mice (Figure 7B). Moreover, we also demonstrated that GL-261 tumor cells infected with RRV-scFv-PDL1 exhibited antitumor activity in a syngeneic orthotopic glioma model in C57BL/6 mice (Supplementary Figure 9). Together, these 
findings indicate that scFv PD-L1 has anti-tumor activity in two glioma tumor models and Tu-2449 tumor model represents a previously undescribed glioma mouse model that responds to checkpoint inhibitors as a monotherapy.

\section{RRV-scFv-PDL1 infected tumors do not secrete appreciable levels of scFv PD-L1 into the systemic circulation}

Since RRV-scFv-PDL1 is delivered as a virus rather than a therapeutic antibody and that ScFv PD-L1 is produced from the infected tumor cells, scFv PD-L1 serum level is anticipated to be significantly lower than the levels reported for therapeutic antibodies delivered intravenously.

A

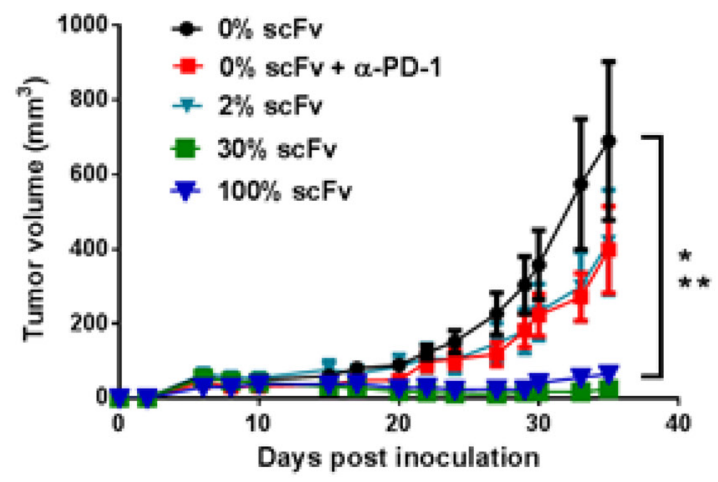

C

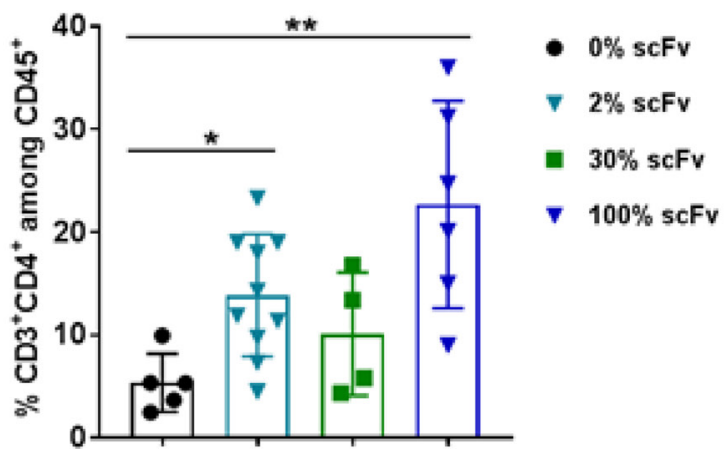

Given the possibility that ScFv PD-L1 may distribute into circulation during tumor lysis, we collected serum from tumor-bearing mice in both subcutaneous and intracranial models that demonstrated anti-tumor activity and measured scFv PD-L1 using a surface plasma resonance method. As expected, our data reveal that the scFv PD-L1 serum concentrations from tumor-bearing mice expressing ScFv PD-L1 were comparable to that of negative control groups in both models (Figure 8A-8D). Although most of the samples measured had signals below the lower limit of quantification (LLOQ), some, particularly from the subcutaneous tumor model, were measured at background level above LLOQ. As these values were observed in mice from the negative control group (100\% RRV-GFP tumor

\section{B}

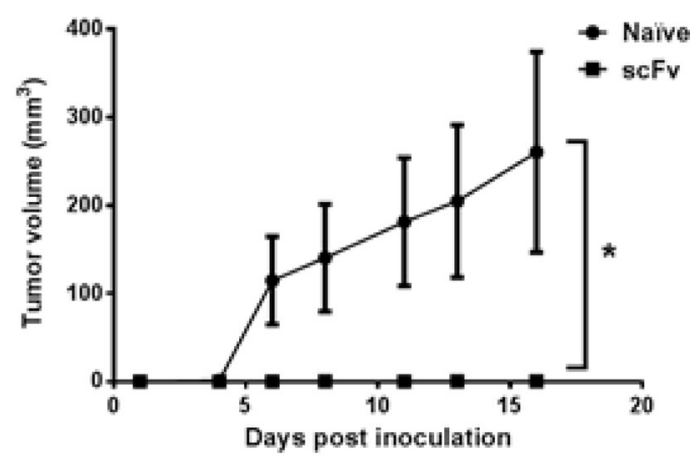

D

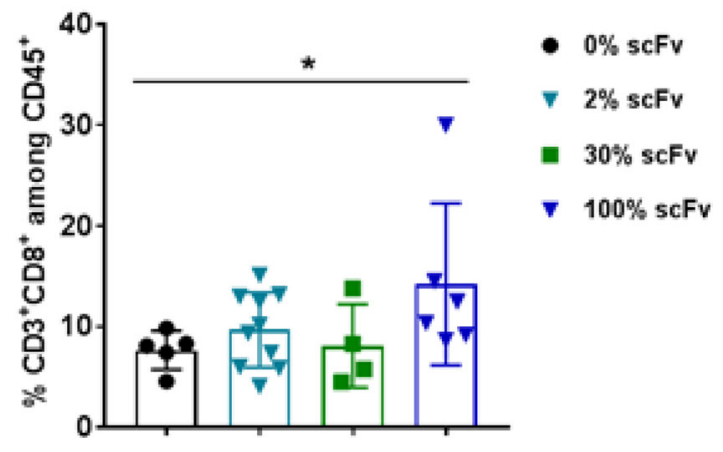

Figure 6: Pre-transduced tumor cells expressing ScFv PD-L1 demonstrate a dose-dependent anti-tumor activity and enhanced tumor infiltrating lymphocytes. (A) Subcutaneous tumor model using Tu-2449SC cells maximally infected with RRVscFv PDL1 or RRV-GFP at indicated ratios were subcutaneously implanted on the right flank of 8-week-old female B6C3F1 mice and assigned to indicated groups ( $n=10$ per group). Control groups are mice implanted with $100 \%$ Tu-2449SC/RRVGFP cells that received PBS $(0 \% \mathrm{scFv})$ or anti-mouse PD-1 antibody $(0 \% \mathrm{scFv}+\alpha$-PD-1). Anti-PD-1 antibody (Clone J43) was i. p. administered on day 0 (300 $\mu \mathrm{g}$ per mouse), day 3, day 6 and day $9(200 \mu \mathrm{g}$ per mouse). Statistical significance was determined by 2-way ANOVA of the following data sets: ${ }^{*} p<0.0001$ for $0 \%$ vs $30 \% \mathrm{scFv} ;{ }^{* *} p<0.0001$ for $0 \%$ vs $100 \% \mathrm{scFv}$. (B) Naïve mice $(n=5)$ and mice that cleared their initial tumor implant from RRV-scFv-PDL1 treated group $(n=15)$ were challenged with $2 \times 10^{6} \mathrm{Tu}-2449 \mathrm{SC}$ on the left side of the flank. Tumor growth and measurement were monitored over time. ${ }^{*} p<0.0001(0 \% \mathrm{scFv}$ vs. $2 \%, 30 \%$ and $100 \% \mathrm{scFv})$. Error bars indicate the standard error measurement (SEM) of the dataset. (C) and (D) Frequency of tumor-infiltrating CD4 ${ }^{+}(\mathrm{C})$ and $\mathrm{CD}^{+}(\mathrm{D})$ lymphocytes among CD45 ${ }^{+}$cells by flow cytometry, 39 days post-tumor implantation. Statistical analyses were performed using Mann-Whitney test at $95 \%$ CI $\left({ }^{*} P<0.05\right.$, $\left.{ }^{* *} P<0.01\right)$. Values represent means $\pm \mathrm{SD}$ of the dataset. 
or tumor treated with isotype antibody), we assume it has no significance and represents a non-specific signal from sample components. These findings indicate that scFv PD-L1 expressing tumor does not lead to prolonged exposure of the protein in the serum, presumably due to a combination of local production, high level of tumor retention, and/or short lifespan of the protein in the absence of an Fc region. In all cases, the nominal detected $\mathrm{scFv}$ PD-L1 serum concentration or presumably a non-specific signal is at least 50 to 150 -fold less than the levels reported for anti-PD-1/PD-L1 therapeutic antibodies approved for various clinical indications.

\section{DISCUSSION}

Checkpoint inhibitor blockade has proven to be a promising treatment across many cancer types. However, they are not always effective and are associated with systemic immune toxicities which can lead to discontinuation of treatment. In this study, as a proof of principle, we have demonstrated that PD-1/PD-L1 mediated immune suppression can be rescued by RRV delivery of a secreted ScFv targeting PD-L1 in tumors and immune infiltrating cells in the TME resulting in increased survival and a protective anti-tumor memory response associated with minimal serum exposure of scFv PD-L1. Most importantly, in contrast to oncolytic virus, the anti-

A

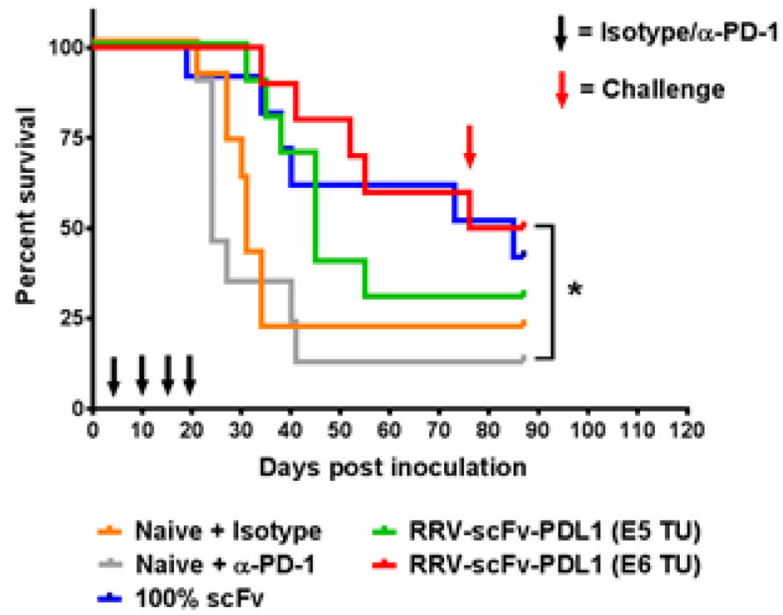

tumor activity observed in tumor-bearing mice treated with RRV-scFv-PDL1 in our studies is not associated with or primed by innate antiviral immunity as shown by $100 \%$ RRV-GFP infected tumor's growth kinetics (included as one of the control groups rather than naïve tumors).

The advantages of using tumor-selective RRV for delivering ScFv PD-L1 in the TME are at least two fold. One is the localized and sustained delivery of therapeutic payload in the TME with relatively short half-life compared to recombinant therapeutic antibodies. These features allow for engagement of the checkpoint to promote anti-tumor activity in TMEs that may be difficult to reach with conventional systemic delivery of CPI monoclonal antibodies and consequent efficacy in otherwise poorly responsive tumors as well as avoidance of undesirable binding to healthy tissue leading to systemic immune toxicity [36]. Another advantage may be the prevention of developing an anti-drug antibody response due to repeated systemic infusion of the biotherapeutic [37, 38]. Innovative approaches to circumvent autoimmune toxicity are currently being evaluated. CX-072, an engineered antibody designed for localized therapeutic activity through reliance on tumor-expressing protease(s) to unmask the antigen binding domain targeting PD-L1 in the TME recently reported a favorable safety profile (http://ir.cytomx.com/news-releases/news-release-details/ cytomx-therapeutics-presents-preliminary-clinical-proof-

\section{B}

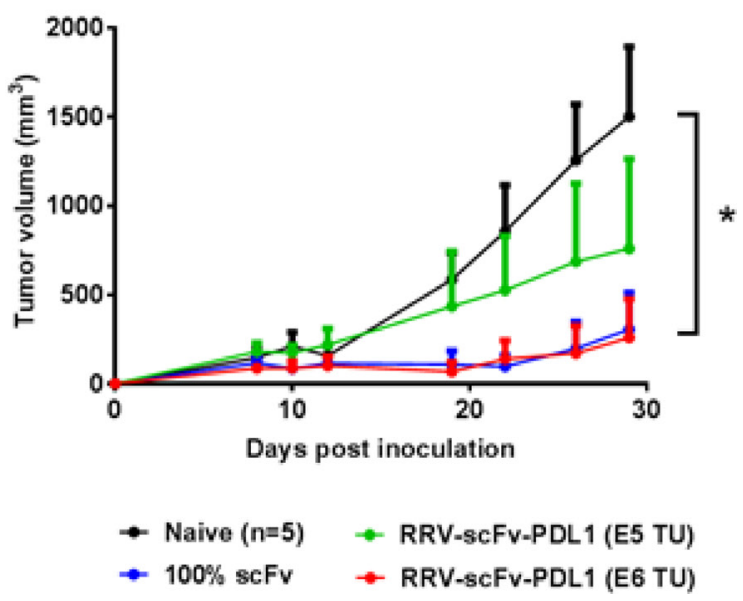

Figure 7: Orthotopic glioma model with intracranial injection of RRV-scFv-PDL1 demonstrates a dose-dependent anti-tumor activity. (A) Female B6C3F1 mice (8-week-old; $n=10$ per group) were i.c. implanted with $1 \times 10^{4}$ of Tu-2449 cells. Survival analysis was monitored for 90 days. Mice in the experimental groups were injected with 1E5 or 1E6 TU of purified RRV-scFvPDL1 vector on day 4 post tumor implant. Control groups are mice bearing $100 \%$ pre-transduced scFv PD-L1 expressing tumor cells $(100 \% \mathrm{scFv})$ and mice treated anti-PD-1 antibody (Naive $+\alpha \mathrm{PD}-1)$ or isotype control (Naive + Isotype), (300 $\mu \mathrm{g}$ per mouse i.p. induction on day 4; $200 \mu \mathrm{g}$ per mouse maintenance dose on day 10, 14 and 17 indicated by black arrows). Survival data were plotted by the KaplanMeier method. Statistical significance of survival between mice treated with anti-PD-1 antibody and injection-treated RRVscFvPDL1 mice was determined by the Log-rank (Mantel-Cox) test, ${ }^{*} p=0.0045$. (B) Mice which had survived from initial tumor implant from RRV-scFvPDL1 pre-transduced or injectiontreated groups were challenged with $2 \times 10^{6} \mathrm{Tu}-2449 \mathrm{SC}$ cells on the right flank on day 80 (red arrow) post primary tumor implant. Tumor growth and measurement were monitored over time. Statistical significance was determined by 2 -way ANOVA of the following data sets: ${ }^{*} p<0.0001$ for Naive vs $1 E 6$ TU RRV-scFv PD-L1. Error bars indicate the SEM of the dataset. 
concept). However and notably, grade 3/4 immune-related toxicity was still identified in some patients.

We and others have previously demonstrated PD-1/ PD-L1 blockade using the RNAi and aptamer approach [39-41]. Nevertheless, limitations of these approaches are related to tumor selectivity and/or lack of a bystander effect. By contrast, overexpression of tumor-selective scFv PD-L1 protein by less than 10\% RRV-scFv-PDL1 infected cells in vitro can fully occupy PD-L1 on bystander cells which translates to a high level of anti-tumor activity in several mouse tumor models. Also, RRV-scFv-PDL1 efficacy was evaluated in several syngeneic mouse tumor models in pre-transduced setting to evaluate dose effect and via intratumoral vector injection to mimic a potential clinical setting. A dose-dependent anti-tumor activity was observed in all three tumor models tested, indicating that $2 \%$ transduction level led to similar therapeutic effect as the anti-PD-1 antibody treated group and that a higher
A

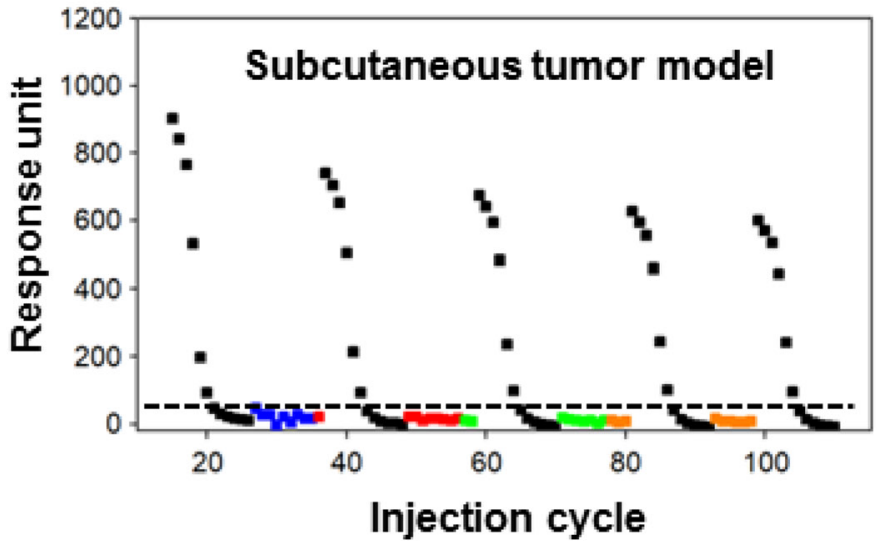

C

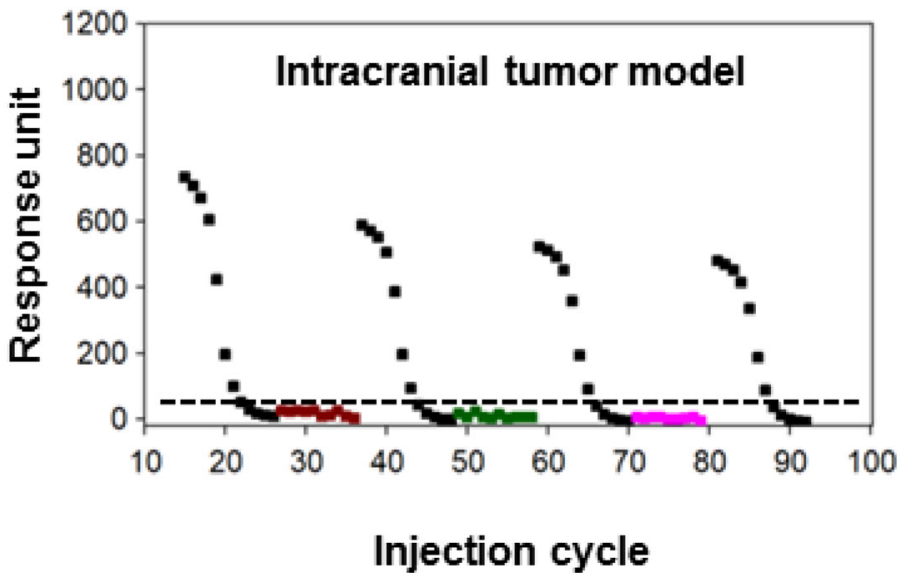

B

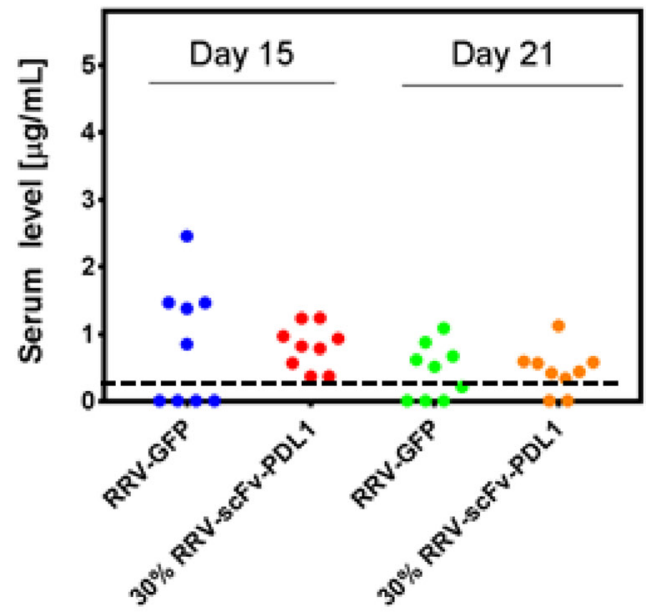

D

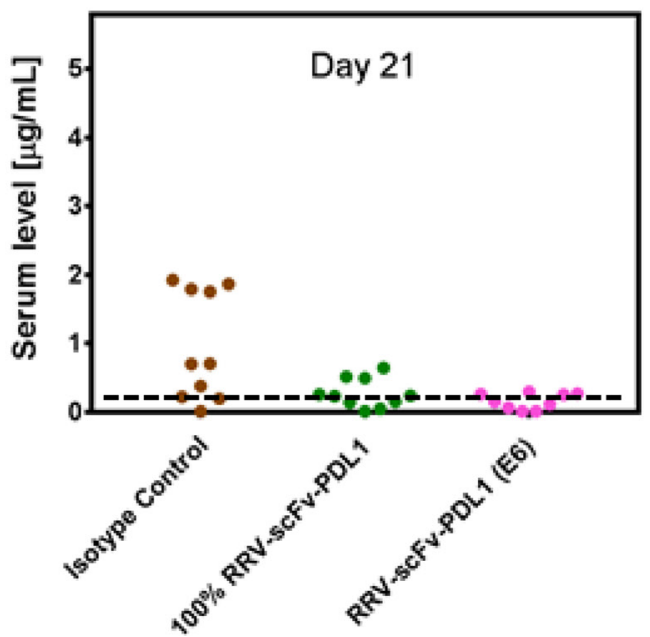

Figure 8: scFv PD-L1 serum levels in tumor-bearing mice. (A, B) Sera from Tu2449 subcutaneous tumor pre-transduced with $30 \%$ RRV-scFv-PDL1 and (C, D) Tu-2449 intracranial tumor treated with isotype, pre-transduced with $100 \%$ RRV-scFv-PDL1 or injected with $1 \times 10^{6} \mathrm{TU}$ of RRV-scFv-PDL1 were collected at indicated time point post tumor implant. scFv PD-L1 serum concentrations were measured by surface plasmon resonance with standard curves at concentrations ranging between $0.1 \mathrm{nM}-200 \mathrm{nM}(0.0028 \mu \mathrm{g} / \mathrm{mL}-5.6 \mu \mathrm{g} /$ $\mathrm{mL}$ ) using naïve serum spiked-in with purified scFv PD-L1 and serve as positive controls. Sera from RRV-GFP pre-transduced tumor or isotype antibody treated tumor-bearing mice were included for baseline levels. Each symbol represents one mouse serum sample. Each colored symbol except black represents one mouse serum sample. Black, standard curves generated for every 20 cycles of regeneration. (B) and (D) Graphical presentation of the data conversion from responsive unit shown in (A) and (C) to $\mu \mathrm{g} / \mathrm{mL}$. The lower limit of quantification (LLOQ) is determined to be $0.011 \mu \mathrm{g} / \mathrm{mL}(0.39 \mathrm{nM})$ and the dashed horizontal line indicates LLOQ of the assay. For graphical presentation, samples measured below LLOQ were entered with a fixed value of $0.010 \mu \mathrm{g} / \mathrm{mL}$. The data represent one data set from two separate experiments. 
transduction level demonstrated anti-tumor activity that is superior than anti-PD-1 antibody group, suggesting the level of PD-L1 occupancy by anti-PD-1 antibody infusion may be suboptimal at the tumor site.

Given that RRV has been demonstrated to be cancerselective both in preclinical and clinical settings [3, 42], an enhanced anti-tumor activity owing to longer half-life than scFv PD-L1 and/or potential antibody-dependent cell-mediated cytotoxicity was not observed in our pretransduced tumor models. To the contrary, the presence of Fc in scFvFc PD-L1 appears to diminish anti-tumor activity which is most evident in the Tu-2449SC tumor model (Supplemental Figure 6). A possible explanation of this phenomenon is suggested by a recent report which revealed that bound anti-PD-1 antibody on T cells can be phagocytosed by PD-1-negative tumor associated macrophages via interaction between the antibody $\mathrm{Fc}$ glycan and Fc $\gamma \mathrm{R}$ on the macrophages, limiting antibody retention in the TME and reducing antibody-induced anti-tumor activity [43]. Importantly, scFv PD-L1 antitumor activity is associated with serum levels below the limit of quantification which is at least 50- to 150fold less than most CPI antibodies levels reported in patients administered antibody systemically (Figure 8). Furthermore, along with proximal target engagement within the TME, a significant, higher binding affinity of scFv PD-L1 to human PD-L1 than human PD-1 to PD-L1 $\left(\mathrm{K}_{\mathrm{D}}=0.426 \mathrm{nM}\right.$ vs $\left.0.77 \mu \mathrm{M}\right)[16]$ as well as a significantly longer half-life of scFv PD-L1 bound to human PD-L1 (Supplementary Figure 1), $\left(\mathrm{t}_{1 / 2}=\sim 77 \mathrm{~min}\right.$ for scFv PDL1/PD-1 vs. $0.9 \mathrm{sec}$ for human PD-L1/PD-1) [44] may provide therapeutic benefits for the RRV TME-centered CPI immunotherapy.

Immunotherapy studies in brain tumor have been limited by the lack of representative murine models. The anti-tumor activity observed in the Tu-2449 syngeneic orthotopic glioma model brings a second model other than GL-261 reported to respond to checkpoint inhibitor as a monotherapy $[34,35,45,46]$. The Tu-2449 tumor has been described to closely resemble the development of human glioblastoma with characteristic of hypervascularization $[47,48]$. Despite the fact the Tu-2449 cells are immunogenic and express MHC on their cell surface (data not shown), unlike GL-261 cells which are reported to carry high tumor mutational burden (Genoud et al., OncoImmunology, https://doi.org/10.1080/2162 402X.2018.1501137), their tumorigenic property is not induced by carcinogen and thus are most likely to have low tumor mutational burden which closely resembles human GBM.

RRV-scFv-PDL1 could potentially be applicable in a neoadjuvant setting prior to tumor resection; this type of use with nivolumab, was recently reported to induce expansion of antigen-specific clones in lung cancer [49]. In addition, the non-essential requirement of $\mathrm{Fc}$ in our tumor- selective RRV delivery platform would allow inclusion of additional TME-targeted therapeutic transgene(s) in the RRV to further alleviate the immunosuppressive TME. For example a treatment leading to tumor lysis in turn leads to dendritic cell recruitment and activation [46, $50,51]$ in combination with removal of T-cell anergy by RRV-scFv-PDL1, could be beneficial. Alternatively, combination therapy of RRV-scFv-PDL1 and therapeutics with very narrow therapeutic indices such as anti-CTLA4 antibody could lead to synergistic anti-tumor activity while reducing immune toxicities reported in current combination therapies.

In conclusion, our study demonstrates that RRVScFV-PDL1 checkpoint inhibition with a tumor-selective delivery and a high bystander index localized within the TME provides an attractive treatment regimen to target immune checkpoints.

\section{MATERIALS AND METHODS}

\section{Construction of RRV-scFv-PDL1 plasmid DNAs}

Two pairs of two different configurations of singlechain variable fragment $(\mathrm{scFv})$ against PD-L1 were designed. One pair consists of $\mathrm{scFv}$ with and without the Fc from human IgG1, designated scFv-PDL1 and scFvFcPDL1, respectively. The other pair consists of scFv-PDL1 and scFvFc-PDL1 with HA and Flag epitope incorporated at the C-terminus, designated scFv-HF-PDL1 and scFvFcHF-PDL1. The coding sequence of each configuration contains the 3 ' coding sequence of the viral envelope gene followed by the gT2A peptide sequence [21] and was synthesized with Asc I and Not I restriction sites for subcloning into pAC3-gT2A-yCD2 at the corresponding sites to replace the $\mathrm{gT} 2 \mathrm{~A}-\mathrm{yCD} 2$ transgene cassette resulting in pAC3-scFv-PDL1, pAC3-scFvFc-PDL1, pAC3-scFv- HF-PDL1, and pAC3-scFvFc-HF-PDL1.

\section{Cell culture}

Human 293T cells (obtained through a material transfer agreement with the Indiana University Vector Production Facility, and Stanford University deposited the cells with ATCC, SD-3515; lot 2634366), human glioma cell line U87-MG (ATCC, HTB-14), mouse colorectal cancer cell line CT26 (ATCC, CRL-2638), mouse breast cancer cell line EMT6 (ATCC, CRL-2755), mouse glioma cell line Tu-2449 [3] and Tu-2449SC [2] were cultured in complete Dulbecco's modified Eagle's medium. Human leukemic T cell line Jurkat Clone E6-1 (ATCC, TIB-152) and human Burkitt's B lymphoma cell line Raji (ATCC, CCL86) were cultured in complete RPMI-1640 medium. All completed medium contains 10\% fetal bovine serum (HyClone), sodium pyruvate (Cellgro), Glutamax and penicillin-streptomycin (Invitrogen). 
Jurkat $\mathrm{T}$ cells and Raji B cells overexpressing human PD-1 (Jurkat/PD-1) and PD-L1(Raji/PD-L1), respectively, were generated by transducing the cells with lentiviral vectors coding human PD-1 or PD-L1 at MOI of 1 followed by puromycin selection $(1.6 \mu \mathrm{g} / \mathrm{mL}) 2$ days post transduction. PD-1 expressing Jurkat T cells and PDL1 expressing Raji B cells were enriched under puromycin selection for 14 days and confirmed by cells surface staining with anti-PD-1 and anti-PD-L1, respectively.

\section{Virus production from $293 \mathrm{~T}$ cells and virus titer}

Twenty micrograms of plasmid DNA encoding the RRVs were used for transient transfection using the calcium phosphate method as previously described [40]. The viral titers of all RRVs were determined by quantitative PCR (qPCR) and viral titers, reported in transduction units per milliliter $(\mathrm{TU} / \mathrm{mL})[5,22]$.

\section{Virus replication kinetics of RRVs in U87-MG cells and vector genome stability}

For viral replication kinetics, $20 \mu \mathrm{L}$ of collected supernatant from each time points during the course of infection were obtained to extract viral RNA and measure particle titer as described [40]. For vector genome stability, genomic DNA from each infection cycle was extracted from maximally infected U87-MG cells using the Maxwell 16 Cell DNA Purification Kit (Promega \# AS1020) as described [22].

\section{Immunoblots}

For the assessment of the transgene protein expression, separation efficiency of the polyproteins, and viral envelop protein processing, cells lysates were prepared as described [21].

\section{scFv PD-L1 bystander trans-binding activity to PD-L1 on the cell surface}

EMT6 cells maximally infected with RRV-scFvHF-PDL1 (HA-tagged scFv-PD-L1) or RRV-GFP at 90\% confluency were treated with recombinant human IFN $\gamma$ at $250 \mathrm{IU} / \mathrm{mL}$ for 24 hours to upregulate PD-L1 expression on the cell surface. One million of IFN $\gamma$-treated EMT6 cells maximally infected with RRVscFv-HF-PDL1 or RRV-GFP at indicated ratios were split into 2 sets. One set of cells was stained with Alexa Fluor 647-conjugated anti-HA antibody (BioLegend, \# 682404) and the second set of cells was stained with PE-conjugated anti-human PD-L1 antibody (ebioscience, \# 12-5983). HA-positive, PD-L1-positive, and GFP-positive cell populations were measured by flow cytometric analysis (FACS Canto, BD Biosciences). HA-positive vs GFP positive cell populations and PD-L1-positive vs GFP-positive cell population were calculated by 2-color compensation for proper gating (BD FACSDiva software, BD Biosciences). Cytometry data analysis was performed using the FlowJo v10 software (FlowJo LCC).

\section{Detection of scFv PD-L1 binding to PD-L1 by competitive ELISA}

Wells in a 96-well microtiter plate were coated with $100 \mu \mathrm{L}$ of $1.5 \mu \mathrm{g} / \mathrm{mL}$ recombinant human PD-L1-Fc (R \& D Systems, \# 156-B7) or mouse PD-L1-Fc (BioLegend, \# 758206) overnight at $4^{\circ} \mathrm{C}$, followed by 2 hour blocking at room temperature with blocking buffer (1X PBS + $10 \%$ FBS $+0.05 \%$ Tween 20 ) the next day. Subsequently, PD-L1-Fc coated wells were co-incubated with $1 \mu \mathrm{g} / \mathrm{mL}$ His-tagged recombinant human PD-1 (SinoBiological, \# 10377-H08H) or His-tagged recombinant mouse PD-1 (abcam, \# ab180051) in competition with supernatant of undefined protein concentration collected from CT26 cells maximally infected with RRV-scFv-PDL1 or RRV-scFvFcPDL1 (100, 50 and $25 \mu \mathrm{L}$ ), anti-PDL1 antibody (antihuman PD-L1, ebioscience \# 14-5983-82; anti-mouse PDL1 BioLegend \# 124302) or purified scFv PDL1 protein (Accelagen Inc.) for 2 hours at room temperature. For interaction between scFv PD-L1 and human PD-L1, bound His-tagged recombinant human PD-1 was detected using an HRP-conjugated anti-6X His tag antibody (Invitrogen, \# PA1-23024). For binding interaction between scFv PDL1 and mouse PD-L1, bound His-tagged recombinant mouse PD-1 was detected by performing an additional signal amplification step using an biotin-conjugated anti-6X His tag antibody (1:3,000), (abcam, \# ab27025) followed by HRP-conjugated streptavidin (1:10,000), (abcam, \# ab7403). Color development was performed by adding 3,3',5,5'-Tetramethylbenzidine (TMB) substrate solution (Southern Biotech, \# 0410-01) and terminated by TMB STOP solution (Southern Biotech, \# 0412-01) after 6-10 minutes incubation. Optical density was read by a plate reader (Molecular Devices iD5) at $450 \mathrm{~nm}$ (with $570 \mathrm{~nm}$ correction) using the Soft Max Pro software. The percentage of inhibition was calculated with respect to a positive control which supernatant from CT26 maximally infected with RRV-GFP (non-scFv-PD-L1) was used in the competition.

\section{In vitro immune function of scFv PD-L1 and IL-2 ELISA}

Jurkat T cells were washed and rested in serumfree RPMI-1640 medium at $37^{\circ} \mathrm{C}$ for 3 hours at $5 \times 10^{5}$ cells $/ 0.5 \mathrm{~mL}$. Raji B cells were washed and resuspended in serum-free RPMI-1640 medium at $1 \times 10^{6}$ cells $/ 0.5 \mathrm{~mL}$ followed by addition of super antigen SEE $(10 \mu \mathrm{g} / \mathrm{mL}$, final concentration), (Toxin Technology \#ET404) or SEE plus anti-human PD-L1 or SEE plus purified $\mathrm{scFV}$ PD-L1 $(10 \mu \mathrm{g} / \mathrm{mL})$ followed by incubation at $37^{\circ} \mathrm{C}$ for 1 hour. At the completion of incubation, SEE loaded Raji 
B cells were washed in serum-free RPMI-1640 medium and resuspended in RPMI-1640 medium containing 20\% human AB serum (Sigma-Aldrich, \# H4522) at $5 \times 10^{5}$ cells $/ 0.5 \mathrm{~mL}$. Both rested Jurkat T cells and SEE-loaded Raji B cells were then co-cultured with equal volumes to reach $1 \times 10^{6}$ cells $/ \mathrm{mL} /$ well in a non-coated $24-$ well plate and incubated at $37^{\circ} \mathrm{C}$ for stimulation.

For IL-2 ELISA, the supernatants of the co-culture cells were collected 20-22 hours after stimulation and separated from the cells by centrifugation at $300 \times \mathrm{g}$ for 5 minutes. IL-2 production was measured by using the Quantikine ELISA Kit (R \& D System, \# D2050) according to the manufacturer's protocol.

\section{Mouse tumor models}

All animal protocols and experiments were approved by the IRB/IACUC of Explora BioLabs (San Diego, CA, USA). For the Tu-2449SC subcutaneous tumor model, $2 \times 10^{6}$ of Tu-2449SC cells maximally infected with RRVscFv-PDL1 or RRV-GFP at indicated ratios were subcutaneously implanted on the right flank of 8-week-old female B6C3F1 mice (Harlan Sprague Dawley Inc.) and assigned to 8 groups ( $n=10$ per group). Control Group 1 and 2 which are mice implanted with $100 \%$ Tu-2449SC/ RRV-GFP cells received PBS or anti-PD-1 antibody. AntiPD-1 antibody (Clone J43) was intraperitoneally (i. p.) administered on day 0 (300 $\mu \mathrm{g}$ per mouse), day 3 , day 6 and day 9 (200 $\mu \mathrm{g}$ per mouse). Group 3, 4, and 5 received ratios of 3/97, 30/70 and 100/0 of Tu-2449SC/RRV-scFvPDL1 and Tu-2449SC/RRV-GFP cells, respectively. Group 6, 7, and 8 received ratios of 3/97, 30/70 and 100/0 of Tu-2449SC/RRV-scFvFc-PDL1 and Tu-2449SC/RRVGFP cells, respectively. Tumor sizes were monitored 3 times a week. Animals were removed from the study if tumors became necrotic or reached $2000 \mathrm{~mm}^{3}$ in volume. All mice that cleared their initial tumor implant from RRVscFv-PDL1 or RRV-scFvFc-PDL1 treated groups $(n=15)$ and naïve group $(n=5)$ were challenged with $2 \times 10^{6} \mathrm{Tu}-$ 2449SC on the left side of the flank. Tumor growth and measurement were monitored and recorded over time.

For the orthotopic glioma model, 8-week-old female B6C3F1 mice underwent surgical implantation of the tumor cells by Hamilton syringe. The stereotaxic coordinates were anteroposterior (AP), $0.5 \mathrm{~mm}$; mediolateral (ML), $1.8 \mathrm{~mm}$; and dorso-ventral (DV), 3.5 $\mathrm{mm}$ (from bregma). Mice in each group $(n=10)$ were intracranially (i.c.) implanted with $1 \times 10^{4}$ of Tu-2449 cells. Survival analysis was monitored for approximately 90 days. Mice in the experimental groups were injected with purified RRV-scFv-PDL1 of $1 \times 10^{5}$ or $1 \times 10^{6}$ transduction unit (TU) on day 4 post tumor implant. Control groups are mice bearing $100 \%$ pre-transduced RRV-scFv-PDL1 tumor cells and Tu-2449SC tumor cells treated anti-PD-1 antibody (300 $\mu \mathrm{g}$ per mouse i.p. induction on day $4 ; 200 \mu \mathrm{g}$ per mouse maintenance dose on day 10, 14 and 17) or isotype control. Survival data were plotted by the Kaplan-Meier method. Statistical significance of survival between mice treated with isotype and $100 \%$ pre-transduced scFv-PD-L1 or injection-treated RRV-scFV-PDL1 groups were determined by the Log-rank (Mantel-Cox) test using GraphPad Prism 7 (GraphPad Software, Inc.). Mice which had survived from initial tumor implant from RRV scFv-PDL1 treated groups were challenged with $2 \times 10^{6} \mathrm{Tu}-2449$ cells on the right flank. Tumor growth and measurement were monitored and recorded over time.

\section{Analysis of tumor infiltrating lymphocytes}

In a separate Tu-2449SC subcutaneous tumor model experiment, mice from each assigned group that showed measurable tumor growth were sacrificed at day 39 post tumor implantation. Tumors were excised from the skin and minced into small pieces in HBSS (ThermoFisher Scientific, \# 14175095) and single-cell suspensions were obtained using gentleMACS ${ }^{\mathrm{TM}} \mathrm{C}$ Tubes with gentleMACS ${ }^{\mathrm{TM}}$ Dissociator (Miltenyi Biotec, \# 130096-334 and \# 130-093-235), and enzymatic solution containing $50 \mu \mathrm{g} / \mathrm{mL}$ final Liberase ${ }^{\mathrm{TM}} \mathrm{TM}$ (Sigma-Aldrich, \# 5401119001) and $200 \mathrm{U} / \mathrm{mL}$ final Deoxyribonuclease I (Sigma Aldrich, \# D5025). After filtration through a $70 \mu \mathrm{m}$ cell strainer and washing, erythrocytes were removed following incubation with eBioscience $1 \mathrm{X}$ RBC Lysis Buffer (ThermoFisher Scientific, \# 00-4300-54). Viable cell counts were determined using a Cellometer K2 (Nexcelom Bioscience). For subsequent flow cytometry analyses, cells were first incubated with TruStain FcX antibody (BioLegend, \# 101320) and Zombie UV (BioLegend, \# 423108) before being subjected to surface staining with fluorochrome-conjugated antibodies against mouse CD45 (BioLegend, \# 103132), CD3ع (BD Biosciences, \# 563565), CD4 (BD Biosciences, \# 564922) and CD8 $\alpha$ (BioLegend, \# 100759). Acquisition was conducted on an LSRFortessa X-20 flow cytometer and analysis by using FlowJo software (version 10) with flowAI (1.7) plugin as described [52].

\section{Measurement of scFv PD-L1 level in serum from tumor-bearing mice}

Recombinant human PD-L1 (R\&D Systems \# 156B7) was immobilized on the CM5 sensorchip surface standard amine coupling chemistry using a Biacore 3000 instrument. The running buffer comprised $25 \mathrm{mM}$ HEPES, pH 7.5, $150 \mathrm{mM} \mathrm{NaCl}, 0.005 \% \mathrm{P}_{20}$ (Tween 20), and $0.5 \mathrm{mg} / \mathrm{mL} \mathrm{BSA}$ at $25^{\circ} \mathrm{C}$. Purified scFv PD-L1 (>95\% purity) at concentrations ranging between $0.01200 \mathrm{nM}$ $(\sim 0.0028 \mu \mathrm{g} / \mathrm{mL}-5.6 \mu \mathrm{g} / \mathrm{mL})$ was spiked into $1: 20(\mathrm{v} / \mathrm{v})$ diluted naïve serum to generate a standard curve for every 10 regeneration cycles. Experimental samples were also prepared at 1:20 dilution and injected in at a flow rate of 
$5 \mu \mathrm{L} /$ min for a 6 -minute contact time. Raw data was analyzed in the Scrubber2 software (BioLogic Software). The lower limit of quantification of this assay is determined to be $0.011 \mu \mathrm{g} / \mathrm{mL}$. The concentration of scFv PD-L1 level in serum was determined using the SoftMax Pro 5.45 software (Molecular Devices) with the standard curves plotted using a 4-parameter fit algorithm.

\section{Author contributions}

AHL, LAM, DJJ, and HEG conceptualized the project; AHL wrote the manuscript. AHL, LAM, KY, AH, SV, AWM, FLE, DM, MERA, SB, AH, MM, WPA, CB, and $\mathrm{DG}$ conducted the experiments.

\section{CONFLICTS OF INTEREST}

LAM, KY, AH, SV, AWM, FLE, DM, MERA, AH, WPA, CB, DG, HEG, DJJ and AHL are or were full time employees of Tocagen and hold stock or stock options in Tocagen.

\section{REFERENCES}

1. Cloughesy TF, Landolfi J, Vogelbaum MA, Ostertag D, Elder JB, Bloomfield S, Carter B, Chen CC, Kalkanis SN, Kesari S, Lai A, Lee IY, Liau LM, et al. Durable complete responses in some recurrent high-grade glioma patients treated with Toca 511 + Toca FC. Neuro-oncol. 2018; 20:1383-92. https://doi.org/10.1093/neuonc/noy075. [PubMed]

2. Mitchell LA, Lopez Espinoza F, Mendoza D, Kato Y, Inagaki A, Hiraoka K, Kasahara N, Gruber HE, Jolly DJ, Robbins JM. Toca 511 gene transfer and treatment with the prodrug, 5-fluorocytosine, promotes durable antitumor immunity in a mouse glioma model. Neuro-oncol. 2017; 19:930-39. https://doi.org/10.1093/neuonc/nox037. [PubMed]

3. Ostertag D, Amundson KK, Lopez Espinoza F, Martin B, Buckley T, Galvão da Silva AP, Lin AH, Valenta DT, Perez OD, Ibañez CE, Chen CI, Pettersson PL, Burnett $\mathrm{R}$, et al. Brain tumor eradication and prolonged survival from intratumoral conversion of 5-fluorocytosine to 5-fluorouracil using a nonlytic retroviral replicating vector. Neuro-oncol. 2012; 14:145-59. https://doi.org/10.1093/ neuonc/nor199. [PubMed]

4. Filley AC, Dey M. Immune System, Friend or Foe of Oncolytic Virotherapy? Front Oncol. 2017; 7:106. https:// doi.org/10.3389/fonc.2017.00106. [PubMed]

5. Lin $\mathrm{AH}$, Burrascano $\mathrm{C}$, Pettersson $\mathrm{PL}$, Ibañez $\mathrm{CE}$, Gruber HE, Jolly DJ. Blockade of type I interferon (IFN) production by retroviral replicating vectors and reduced tumor cell responses to IFN likely contribute to tumor selectivity. J Virol. 2014; 88:10066-77. https://doi. org/10.1128/JVI.02300-13. [PubMed]
6. Emens LA, Ascierto PA, Darcy PK, Demaria S, Eggermont AM, Redmond WL, Seliger B, Marincola FM. Cancer immunotherapy: opportunities and challenges in the rapidly evolving clinical landscape. Eur J Cancer. 2017; 81:116-29. https://doi.org/10.1016/j.ejca.2017.01.035. [PubMed]

7. Cousin S, Seneschal J, Italiano A. Toxicity profiles of immunotherapy. Pharmacol Ther. 2018; 181:91-100. https:// doi.org/10.1016/j.pharmthera.2017.07.005. [PubMed]

8. Postow MA, Sidlow R, Hellmann MD. Immune-Related Adverse Events Associated with Immune Checkpoint Blockade. N Engl J Med. 2018; 378:158-68. https://doi. org/10.1056/NEJMra1703481. [PubMed]

9. Suarez-Almazor ME, Kim ST, Abdel-Wahab N, Diab A. Review: Immune-Related Adverse Events With Use of Checkpoint Inhibitors for Immunotherapy of Cancer. Arthritis Rheumatol. 2017; 69:687-99. https://doi. org/10.1002/art.40043. [PubMed]

10. Brahmer JR, Tykodi SS, Chow LQ, Hwu WJ, Topalian SL, Hwu P, Drake CG, Camacho LH, Kauh J, Odunsi K, Pitot HC, Hamid O, Bhatia S, et al. Safety and activity of anti-PD-L1 antibody in patients with advanced cancer. N Engl J Med. 2012; 366:2455-65. https://doi.org/10.1056/ NEJMoa1200694. [PubMed]

11. Topalian SL, Hodi FS, Brahmer JR, Gettinger SN, Smith DC, McDermott DF, Powderly JD, Carvajal RD, Sosman JA, Atkins MB, Leming PD, Spigel DR, Antonia SJ, et al. Safety, activity, and immune correlates of anti-PD-1 antibody in cancer. N Engl J Med. 2012; 366:2443-54. https://doi.org/10.1056/NEJMoa1200690. [PubMed]

12. Deng R, Bumbaca D, Pastuskovas CV, Boswell CA, West D, Cowan KJ, Chiu H, McBride J, Johnson C, Xin Y, Koeppen H, Leabman M, Iyer S. Preclinical pharmacokinetics, pharmacodynamics, tissue distribution, and tumor penetration of anti-PD-L1 monoclonal antibody, an immune checkpoint inhibitor. MAbs. 2016; 8:593-603. https://doi.org/10.1080/19420862.2015.1136043. [PubMed]

13. Lee CM, Tannock IF. The distribution of the therapeutic monoclonal antibodies cetuximab and trastuzumab within solid tumors. BMC Cancer. 2010; 10:255. https://doi. org/10.1186/1471-2407-10-255. [PubMed]

14. Ott PA, Hodi FS, Robert C. CTLA-4 and PD-1/PD-L1 blockade: new immunotherapeutic modalities with durable clinical benefit in melanoma patients. Clin Cancer Res. 2013; 19:5300-09. https://doi.org/10.1158/1078-0432.CCR13-0143. [PubMed]

15. Blank C, Kuball J, Voelkl S, Wiendl H, Becker B, Walter B, Majdic O, Gajewski TF, Theobald M, Andreesen R, Mackensen A. Blockade of PD-L1 (B7-H1) augments human tumor-specific $\mathrm{T}$ cell responses in vitro. Int $\mathrm{J}$ Cancer. 2006; 119:317-27. https://doi.org/10.1002/ijc.21775. [PubMed]

16. Butte MJ, Keir ME, Phamduy TB, Sharpe AH, Freeman GJ. Programmed death-1 ligand 1 interacts specifically with the B7-1 costimulatory molecule to inhibit $\mathrm{T}$ cell responses. 
Immunity. 2007; 27:111-22. https://doi.org/10.1016/j. immuni.2007.05.016. [PubMed]

17. Sharpe AH, Wherry EJ, Ahmed R, Freeman GJ. The function of programmed cell death 1 and its ligands in regulating autoimmunity and infection. Nat Immunol. 2007; 8:239-45. https://doi.org/10.1038/nil443. [PubMed]

18. Chen DS, Irving BA, Hodi FS. Molecular pathways: nextgeneration immunotherapy - inhibiting programmed deathligand 1 and programmed death-1. Clin Cancer Res. 2012; 18:6580-87. https://doi.org/10.1158/1078-0432.CCR-121362. [PubMed]

19. Taube JM, Anders RA, Young GD, Xu H, Sharma R, McMiller TL, Chen S, Klein AP, Pardoll DM, Topalian SL, Chen L. Colocalization of inflammatory response with B7-h1 expression in human melanocytic lesions supports an adaptive resistance mechanism of immune escape. Sci Transl Med. 2012; 4:127ra37. https://doi.org/10.1126/ scitranslmed.3003689. [PubMed]

20. Parsa AT, Waldron JS, Panner A, Crane CA, Parney IF, Barry JJ, Cachola KE, Murray JC, Tihan T, Jensen MC, Mischel PS, Stokoe D, Pieper RO. Loss of tumor suppressor PTEN function increases B7-H1 expression and immunoresistance in glioma. Nat Med. 2007; 13:84-88. https://doi.org/10.1038/nm1517. [PubMed]

21. Hofacre A, Yagiz K, Mendoza D, Lopez Espinoza F, Munday AW, Burrascano C, Singer O, Gruber HE, Jolly DJ, Lin AH. Efficient Therapeutic Protein Expression Using Retroviral Replicating Vector with 2A Peptide in Cancer Models. Hum Gene Ther. 2018; 29:437-51. https://doi. org/10.1089/hum.2017.205. [PubMed]

22. Perez OD, Logg CR, Hiraoka K, Diago O, Burnett R, Inagaki A, Jolson D, Amundson K, Buckley T, Lohse D, Lin A, Burrascano C, Ibanez C, et al. Design and selection of Toca 511 for clinical use: modified retroviral replicating vector with improved stability and gene expression. Mol Ther. 2012; 20:1689-98. https://doi.org/10.1038/ mt.2012.83. [PubMed]

23. Engeland CE, Grossardt C, Veinalde R, Bossow S, Lutz D, Kaufmann JK, Shevchenko I, Umansky V, Nettelbeck DM, Weichert W, Jäger D, von Kalle C, Ungerechts G. CTLA-4 and PD-L1 checkpoint blockade enhances oncolytic measles virus therapy. Mol Ther. 2014; 22:1949-59. https:// doi.org/10.1038/mt.2014.160. [PubMed]

24. Murakami T. Retroviral env glycoprotein trafficking and incorporation into virions. Mol Biol Int. 2012; 2012:682850. https://doi.org/10.1155/2012/682850. [PubMed]

25. Hui E, Cheung J, Zhu J, Su X, Taylor MJ, Wallweber HA, Sasmal DK, Huang J, Kim JM, Mellman I, Vale RD. T cell costimulatory receptor CD28 is a primary target for PD-1mediated inhibition. Science. 2017; 355:1428-33. https:// doi.org/10.1126/science.aaf1292. [PubMed]

26. Selby MJ, Engelhardt JJ, Johnston RJ, Lu LS, Han M, Thudium K, Yao D, Quigley M, Valle J, Wang C, Chen B, Cardarelli PM, Blanset D, Korman AJ. Preclinical Development of Ipilimumab and Nivolumab Combination
Immunotherapy: Mouse Tumor Models, In Vitro Functional Studies, and Cynomolgus Macaque Toxicology. PLoS One. 2016; 11:e0161779. https://doi.org/10.1371/journal. pone.0161779. [PubMed]

27. Selby MJ, Engelhardt JJ, Quigley M, Henning KA, Chen T, Srinivasan M, Korman AJ. Anti-CTLA-4 antibodies of IgG2a isotype enhance antitumor activity through reduction of intratumoral regulatory $\mathrm{T}$ cells. Cancer Immunol Res. 2013; 1:32-42. https://doi.org/10.1158/2326-6066.CIR-130013. [PubMed]

28. Lau J, Cheung J, Navarro A, Lianoglou S, Haley B, Totpal K, Sanders L, Koeppen H, Caplazi P, McBride J, Chiu H, Hong R, Grogan J, et al. Tumour and host cell PD-L1 is required to mediate suppression of anti-tumour immunity in mice. Nat Commun. 2017; 8:14572. https://doi.org/10.1038/ ncomms 14572. [PubMed]

29. Zippelius A, Schreiner J, Herzig P, Müller P. Induced PD-L1 expression mediates acquired resistance to agonistic anti-CD40 treatment. Cancer Immunol Res. 2015; 3:23644. https://doi.org/10.1158/2326-6066.CIR-14-0226. [PubMed]

30. Filley AC, Henriquez M, Dey M. Recurrent glioma clinical trial, CheckMate-143: the game is not over yet. Oncotarget. 2017; 8:91779-94. https://doi.org/10.18632/ oncotarget.21586. [PubMed]

31. Omuro A, Vlahovic G, Lim M, Sahebjam S, Baehring J, Cloughesy T, Voloschin A, Ramkissoon SH, Ligon KL, Latek R, Zwirtes R, Strauss L, Paliwal P, et al. Nivolumab with or without ipilimumab in patients with recurrent glioblastoma: results from exploratory phase I cohorts of CheckMate 143. Neuro-oncol. 2018; 20:674-86. https://doi. org/10.1093/neuonc/nox208. [PubMed]

32. Berghoff AS, Kiesel B, Widhalm G, Rajky O, Ricken G, Wöhrer A, Dieckmann K, Filipits M, Brandstetter A, Weller M, Kurscheid S, Hegi ME, Zielinski CC, et al. Programmed death ligand 1 expression and tumorinfiltrating lymphocytes in glioblastoma. Neuro-oncol. 2015; 17:1064-75. https://doi.org/10.1093/neuonc/nou307. [PubMed]

33. Garg AD, Vandenberk L, Van Woensel M, Belmans J, Schaaf M, Boon L, De Vleeschouwer S, Agostinis P. Preclinical efficacy of immune-checkpoint monotherapy does not recapitulate corresponding biomarkers-based clinical predictions in glioblastoma. Oncolmmunology. 2017; 6:e1295903. https://doi.org/10.1080/21624 02X.2017.1295903. [PubMed]

34. Reardon DA, Gokhale PC, Klein SR, Ligon KL, Rodig SJ, Ramkissoon SH, Jones KL, Conway AS, Liao X, Zhou J, Wen PY, Van Den Abbeele AD, Hodi FS, et al. Glioblastoma Eradication Following Immune Checkpoint Blockade in an Orthotopic, Immunocompetent Model. Cancer Immunol Res. 2016; 4:124-35. https://doi.org/10.1158/2326-6066. CIR-15-0151. [PubMed]

35. Wainwright DA, Chang AL, Dey M, Balyasnikova IV, Kim CK, Tobias A, Cheng Y, Kim JW, Qiao J, Zhang L, 
Han Y, Lesniak MS. Durable therapeutic efficacy utilizing combinatorial blockade against IDO, CTLA-4, and PD-L1 in mice with brain tumors. Clin Cancer Res. 2014; 20:5290 301. https://doi.org/10.1158/1078-0432.CCR-14-0514. [PubMed]

36. Knowles SM, Wu AM. Advances in immuno-positron emission tomography: antibodies for molecular imaging in oncology. J Clin Oncol. 2012; 30:3884-92. https://doi. org/10.1200/JCO.2012.42.4887. [PubMed]

37. Brunn ND, Mauze S, Gu D, Wiswell D, Ueda R, Hodges D, Beebe AM, Zhang S, Escandón E. The Role of Anti-Drug Antibodies in the Pharmacokinetics, Disposition, Target Engagement, and Efficacy of a GITR Agonist Monoclonal Antibody in Mice. J Pharmacol Exp Ther. 2016; 356:574 86. https://doi.org/10.1124/jpet.115.229864. [PubMed]

38. Shankar G, Shores E, Wagner C, Mire-Sluis A. Scientific and regulatory considerations on the immunogenicity of biologics. Trends Biotechnol. 2006; 24:274-80. https://doi. org/10.1016/j.tibtech.2006.04.001. [PubMed]

39. Lai WY, Huang BT, Wang JW, Lin PY, Yang PC. A Novel PD-L1-targeting Antagonistic DNA Aptamer With Antitumor Effects. Mol Ther Nucleic Acids. 2016; 5:e397. https://doi.org/10.1038/mtna.2016.102. [PubMed]

40. Lin AH, Twitty CG, Burnett R, Hofacre A, Mitchell LA, Espinoza FL, Gruber HE, Jolly DJ. Retroviral Replicating Vector Delivery of miR-PDL1 Inhibits Immune Checkpoint PDL1 and Enhances Immune Responses In Vitro. Mol Ther Nucleic Acids. 2017; 6:221-32. https://doi.org/10.1016/j. omtn.2016.11.007. [PubMed]

41. Prodeus A, Abdul-Wahid A, Fischer NW, Huang EH, Cydzik M, Gariépy J. Targeting the PD-1/PD-L1 Immune Evasion Axis With DNA Aptamers as a Novel Therapeutic Strategy for the Treatment of Disseminated Cancers. Mol Ther Nucleic Acids. 2015; 4:e237. https://doi.org/10.1038/ mtna.2015.11. [PubMed]

42. Cloughesy TF, Landolfi J, Hogan DJ, Bloomfield S, Carter B, Chen CC, Elder JB, Kalkanis SN, Kesari S, Lai A, Lee IY, Liau LM, Mikkelsen T, et al. Phase 1 trial of vocimagene amiretrorepvec and 5-fluorocytosine for recurrent highgrade glioma. Sci Transl Med. 2016; 8:341ra75. https://doi. org/10.1126/scitranslmed.aad9784. [PubMed]

43. Arlauckas SP, Garris CS, Kohler RH, Kitaoka M, Cuccarese MF, Yang KS, Miller MA, Carlson JC, Freeman GJ, Anthony RM, Weissleder R, Pittet MJ. In vivo imaging reveals a tumor-associated macrophage-mediated resistance pathway in anti-PD-1 therapy. Sci Transl Med. 2017; 9:eaal3604. https://doi.org/10.1126/scitranslmed.aal3604. [PubMed]

44. Liang Z, Tian Y, Cai W, Weng Z, Li Y, Zhang H, Bao Y, Li Y. High-affinity human PD-L1 variants attenuate the suppression of $\mathrm{T}$ cell activation. Oncotarget. 2017; 8:88360-75. https://doi.org/10.18632/oncotarget.21729. [PubMed]

45. Agarwalla P, Barnard Z, Fecci P, Dranoff G, Curry WT Jr. Sequential immunotherapy by vaccination with GM-CSF-expressing glioma cells and CTLA-4 blockade effectively treats established murine intracranial tumors. J Immunother. 2012; 35:385-89. https://doi.org/10.1097/ CJ.0b013e3182562d59. [PubMed]

46. Vom Berg J, Vrohlings M, Haller S, Haimovici A, Kulig P, Sledzinska A, Weller M, Becher B. Intratumoral IL-12 combined with CTLA-4 blockade elicits T cell-mediated glioma rejection. J Exp Med. 2013; 210:2803-11. https:// doi.org/10.1084/jem.20130678. [PubMed]

47. Theurillat JP, Hainfellner J, Maddalena A, Weissenberger J, Aguzzi A. Early induction of angiogenetic signals in gliomas of GFAP-v-src transgenic mice. Am J Pathol. 1999; 154:581-90. https://doi.org/10.1016/S0002-9440(10)653035. [PubMed]

48. Weissenberger J, Steinbach JP, Malin G, Spada S, Rülicke T, Aguzzi A. Development and malignant progression of astrocytomas in GFAP-v-src transgenic mice. Oncogene. 1997; 14:2005-13. https://doi.org/10.1038/sj.onc.1201168. [PubMed]

49. Forde PM, Chaft JE, Smith KN, Anagnostou V, Cottrell TR, Hellmann MD, Zahurak M, Yang SC, Jones DR, Broderick S, Battafarano RJ, Velez MJ, Rekhtman N, et al. Neoadjuvant PD-1 Blockade in Resectable Lung Cancer. N Engl J Med. 2018; 378:1976-86. https://doi.org/10.1056/ NEJMoa1716078. [PubMed]

50. Fucikova J, Truxova I, Hensler M, Becht E, Kasikova L, Moserova I, Vosahlikova S, Klouckova J, Church SE, Cremer I, Kepp O, Kroemer G, Galluzzi L, et al. Calreticulin exposure by malignant blasts correlates with robust anticancer immunity and improved clinical outcome in AML patients. Blood. 2016; 128:3113-24. https://doi. org/10.1182/blood-2016-08-731737. [PubMed]

51. Hernandez MG, Shen L, Rock KL. CD40-CD40 ligand interaction between dendritic cells and CD8+ T cells is needed to stimulate maximal $\mathrm{T}$ cell responses in the absence of CD4+ T cell help. J Immunol. 2007; 178:2844-52. https://doi.org/10.4049/jimmunol.178.5.2844. [PubMed]

52. Monaco $\mathrm{G}$, Chen $\mathrm{H}$, Poidinger $\mathrm{M}$, Chen J, de Magalhães JP, Larbi A. flowAI: automatic and interactive anomaly discerning tools for flow cytometry data. Bioinformatics. 2016; 32:2473-80. https://doi.org/10.1093/bioinformatics/ btw191. [PubMed] 